\title{
ASSESSMENT OF THE KNOWLEDGE AND PERCEPTION OF MYPLATE AND DIETARY TRENDS AMONGST UNDERGRADUATE COLLEGE STUDENTS
}

A thesis submitted to the Kent State University College of Education, Health, and Human Services in partial fulfillment of the requirements for the degree of Master of Science

Sarah Radcliff 
(C) Copyright, 2019 by Sarah M. Radcliff

All Rights Reserved 
A thesis written by

Sarah Marie Radcliff

B.S., Kent State University, 2017

M.S., Kent State University, 2019

Approved by

Dr. David Erickson Sharp

, Director, Master's Thesis Committee

, Member, Master's Thesis Committee

Dr. Eun-Jeong Ha

, Member, Master's Thesis Committee

Emily Baker

Accepted by

, Director, School of Health Sciences

Ellen Glickman

, Dean, College of Education, Health, and Human Services

James C. Hannon 
RADCLIFF, SARAH MARIE, M.S., May 2019

Nutrition and Dietetics

NUTRITION KNOWLEDGE AND PERCEPTION OF VEGETARIAN DIETS IN VEGETARIAN AND NON-VEGETARIAN, MALE AND FEMALE COLLEGE STUDENTS

Director of Thesis: Dr. David Erickson Sharp

pp 117

MyPlate is the current food guide image that was created by the United States Department of Agriculture (USDA) in 2011 to teach Americans proper nutrition intake. The MyPlate website provides curriculum for kids age 6-11 as well as a toolkit and resources for college campuses. Students who are now 19 years old would have been within that first wave of students who would have been taught MyPlate curriculum instead of MyPyramid. Because college is when teens typically start making food choices on their own and developing habits to carry them into adulthood, it is important that they understand the basics of nutrition. The purpose of this study was to understand the knowledge of MyPlate and the perception of its utility among undergraduate students between the ages of 18-24. Participants were limited to male and female undergraduate students between the ages of 18-24, who completed an online survey with demographic, knowledge and perception questions. Analysis of the data showed a significant correlation between knowledge of MyPlate and perception of MyPlate utility. $(p=<.05)$. We also looked at dietary trends and compared them to MyPlate recommendations. We found that although students could directly identify MyPlate, they were not necessarily meeting recommendations. Further studies with a larger population and a larger emphasis on dietary intake are needed to confirm the results of this study. 


\section{ACKNOWLEDGEMENTS}

I would like to thank Dr. David Sharp for his guidance and advice throughout this process. When starting graduate school, the idea of understanding journal articles, conducting research, and disseminating data is extremely overwhelming. However, with the help of Dr. Sharp, I was able to understand the importance of good research and how to tackle the writing process one step at a time. I learned so much throughout this process and feel much more confident in my ability to interpret research and understand statistics. Dr. Sharp put a great deal of time, effort, and particularly, patience, while guiding me throughout this process. I look forward to starting my career in the field of nutrition/dietetics and being able to use my newly acquired research skills to aid in my ability to teach others.

I would also like to thank Dr. Eun-Jeong Ha and Emily Baker for their guidance and advice. Without Dr. Ha's vast knowledge of the research process, I would have not been able to expand my personal knowledge of research. Dr. Ha has made a lasting impact on my overall nutrition knowledge and passion as she has supported and taught me throughout both my undergraduate and graduate degrees. Her knowledge of and dedication to nutrition academics is inspiring and something I will carry with me through my career.

I want to thank Emily for being such a solid foundation in my graduate studies. Her patience and kindness helped get me through the combined dietetic internship and master's program here at Kent State. She has supported me, motivated me, and inspired 
me throughout this entire process to always believe "I can do it. Additionally, I would like to thank the undergraduate students at Kent State University who participated in the survey I distributed. Without their participation, data collection would not have been possible.

Lastly, I want to thank my parents, Laura and Steve Radcliff, and my sisters, Molly and Caryn Radcliff for the help and support I received. They have stood by me through my entire education process and have kept me calm and focused. My parents have given me the opportunity of obtaining a high degree of education and for that I am forever grateful. 


\section{TABLE OF CONTENTS}

Page

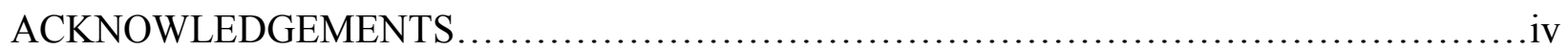

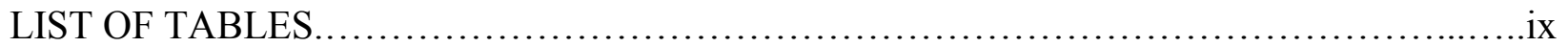

\section{CHAPTER}

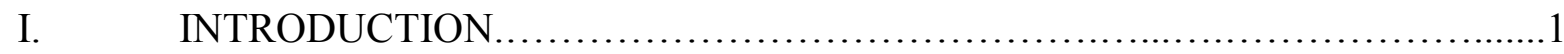

Statement of the Problem.....................................................

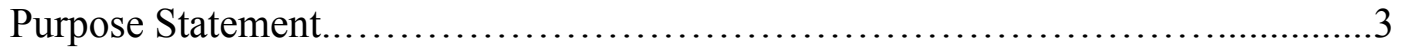

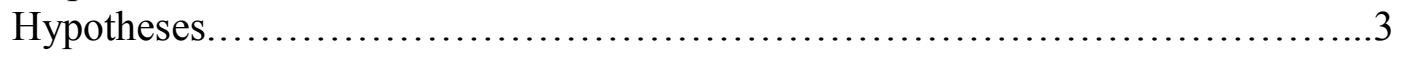

II. REVIEW OF LITERATURE........................................4

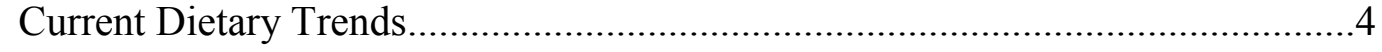

Preparing Food at Home............................................. 7

Consuming Food Outside the Home.................................... 9

Meals, Snacks, and Eating Frequency............................... 10

Health Implications Related to Diet.................................... 12

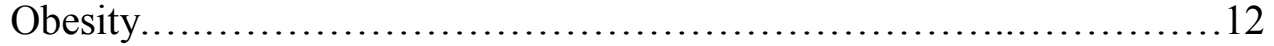

Prevalence..................................................13

Causes of Obesity.............................................. 14

Food processing.......................................14

Nutrient intake............................................ 16

Physical activity ......................................... 17

Chronic Diseases...................................................... 18

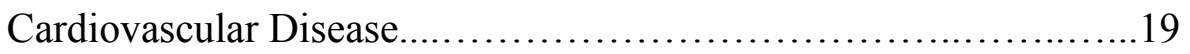

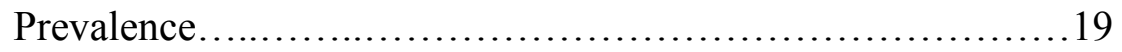

Risk factors...........................................20

Physical activity..........................................21

Dietary implication.......................................22

Diabetes.................................................24

Prevalence.............................................25

Risk factors and diagnosis.................................. 25

Physical activity.........................................27

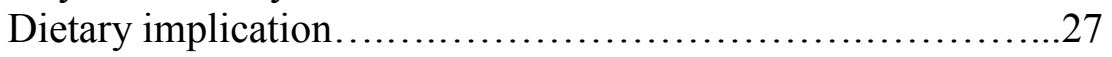

Cancer.........................................................29

Prevalence........................................... 30

Risk Factors.............................................. 30

Dietary Implications........................................ 32

Dietary Guidelines and Recommendations...............................34 
Current Dietary Guidelines...........................................35

MyPlate................................................ 36

Downfalls of MyPlate...............................38

Effectiveness of MyPlate.................................39

College Students ................................................. 40

Dietary trends in college students................................41

College students' food knowledge................................43

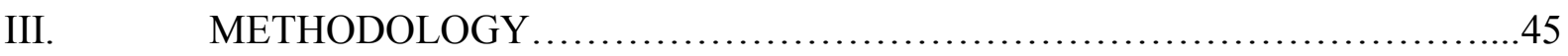

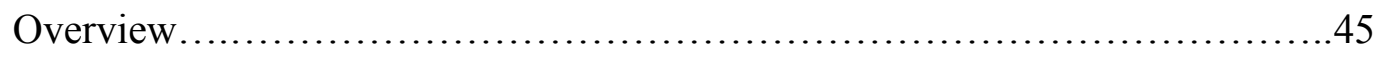

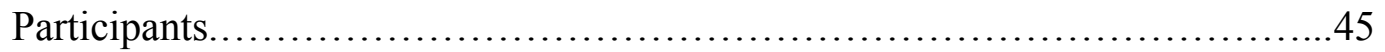

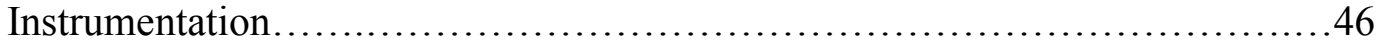

Survey Development............................................ 46

Survey components....................................46

Part I: Demographics.................................47

Part II: Exclusion question and knowledge questions.........47

Part III: Perception questions..............................48

Data Collection Procedures................................................. 48

Data Analysis Procedures.................................................49

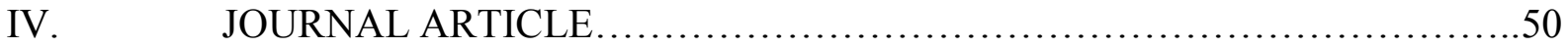

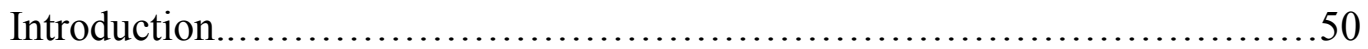

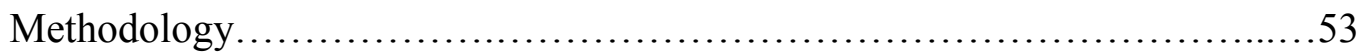

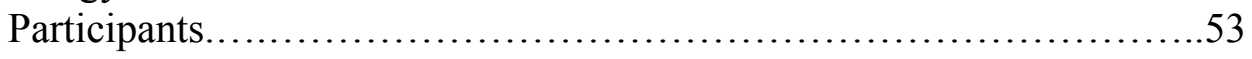

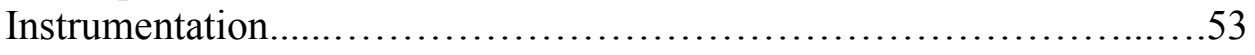

Qualtrics survey.......................................54

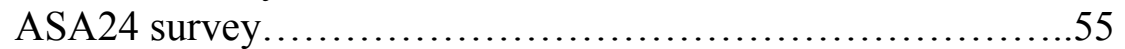

Data Collection Procedures...........................................55

Data Analysis Procedures.........................................56

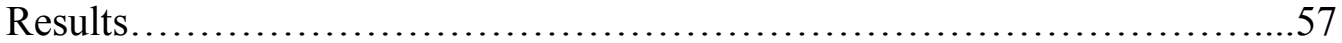

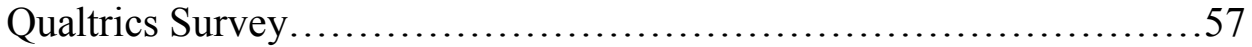

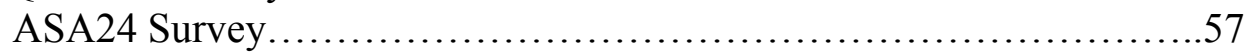

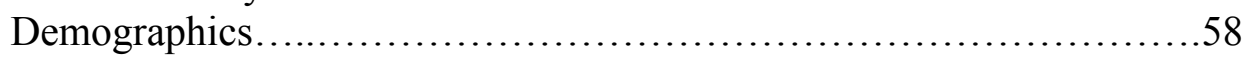

Knowledge of MyPlate..............................................58

Perception of MyPlate Utility.........................................59

Correlation between knowledge and perception of MyPlate...............66

Adherence to MyPlate from sample population.........................67

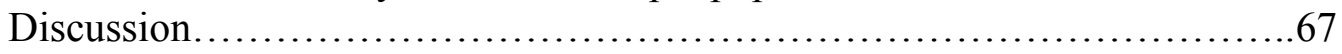

Characteristics of Study Population..................................68

MyPlate Knowledge.................................................

Perception of MyPlate Utility........................................ 72

Dietary Patterns and Adherence to MyPlate............................ 73

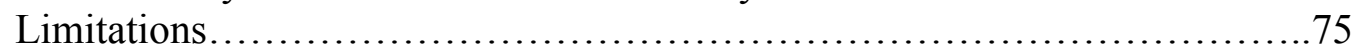


Conclusion............................................................. 76

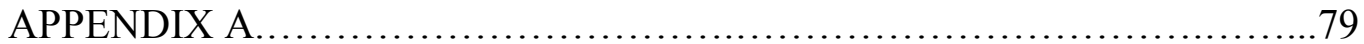

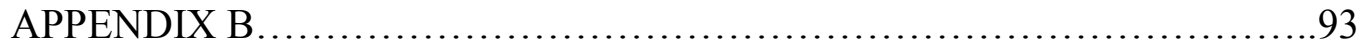

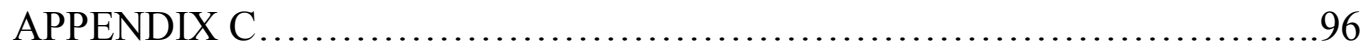

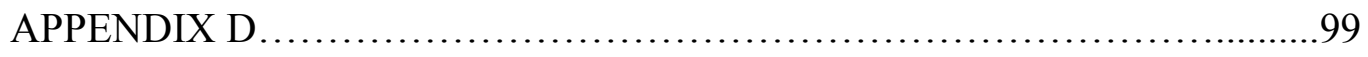

REFERENCES.......................................................... 100 


\section{LIST OF TABLES}

Table

Increasing BMI and Obesity Trends among Adults 20 years

Page

1 and Older from 1988-1994 through 2014

Diagnostic Criteria for Diabetes and Prediabetes. Values taken

2 from Krause's Food and the Nutrition Care Process.

Demographics of Undergraduate Students Surveyed at a

3 Midwestern University on MyPlate Knowledge and Perceived Utility $(\mathrm{N}=1018)$

Answers to Knowledge Questions Regarding MyPlate from

4 Undergraduate Students Surveyed at a Midwestern University $(\mathrm{N}=1018)$

Perception of MyPlate Utility Amongst Undergraduate College

5 Students Surveyed at a Midwestern University $(\mathrm{N}=1018) \ldots \ldots \ldots$

Knowledge and Perception Scores of Male and Female

6 Undergraduate Students Surveyed at a Midwestern University..

Percent of Knowledge Questions Answered Correctly Between

7 Males and Females either Previously/ Currently Enrolled in a

Nutrition Class Versus Males and Females Never Enrolled in a 65

Nutrition Class

Difference in Perception Scores Between Males and Females

8 Previously/Currently enrolled in a Nutrition Class Versus

Males and Females Never Enrolled in a Nutrition Class........

Correlation Between Knowledge and Perception of MyPlate

9 amongst Undergraduate College Students at a Midwestern

State University $(\mathrm{N}=1018)$

10 Average Recommended Intake of Each Food Group Compared to Actual Average Intake From 24-Hour Dietary Recall......... 


\section{CHAPTER I}

\section{INTRODUCTION}

The United States Department of Agriculture (USDA) has been publishing food guides for distribution to the American consumer since 1916 (ChooseMyPlate.gov, 2017). The current food guide, known as MyPlate, promotes recommendations through an illustration of what a well-balanced diet should look like across the lifespan. According to the USDA, recommendations are made for the major food groups in order to promote optimal nutrition and reduce obesity levels. MyPlate encourages the consumption of all five food groups; fruits, vegetables, grains, protein foods, and dairy, as well as choosing foods that are low in saturated fat, sodium, and added sugars (ChooseMyPlate, 2018). In addition, MyPlate can be used to implement the Dietary Guidelines for Americans (DGA) which is currently published by the Department of Health and Human Services (HHS) and the USDA, and updated every five years (Sifferlin, 2016).

The DGA was created in 1980 and continues to be revised in order to provide professionals with the latest scientific evidence and public health trends (Dietary Guidelines for Americans, 2015). Public health data is gathered, analyzed, and used to determine the strengths and weaknesses of a 'typical' American diet. Professionals can utilize the DGA to promote adequate nutrient and energy intake amongst consumers and minimize risk of chronic diseases, such as cardiovascular disease (CVD), diabetes, and certain cancers. Despite the efforts of the HHS and USDA, rates of overweight and obesity have continued to rise over the past three decades with six in ten Americans 
living with at least one chronic disease (Hales, Carroll, Fryar, \& Ogden, 2017; CDC, 2018). It is important to note that prevalence of suboptimal health statuses increases because poor diet has been strongly associated with risk of chronic disease, overweight, and obesity (Dietary Guidelines for Americans, 2015). A poor diet can include the overconsumption of saturated fat, trans fat, sodium, added sugars, and refined grains as well as inadequate consumption of fruits, vegetables, protein foods, whole grains, dairy, and oils. MyPlate recommends filling half of every plate with fruits and vegetables, yet over eighty percent of the population ages one year and older consume fewer than the daily recommended amount of vegetables. MyPlate also recommends limiting saturated fat, added sugars, and sodium, yet over $60 \%$ of the population overconsumes all of these nutrients (Dietary Guidelines for Americans, 2015).

\section{Statement of the Problem}

Dietary guidelines been around since 1916 (ChooseMyPlate.gov, 2017).

According to the USDA, recommendations are made for the major food groups in order to promote optimal nutrition and reduce obesity levels. These recommendations include fruits, vegetables, whole grains, meat, dairy, added sugars, sodium, fats, and saturated fats. It is hypothesized that accurately following these guidelines will lead to a reduction in both excess weight as well as chronic diseases such as diabetes, cardiovascular disease, and cancer. However, Americans with access to these guidelines do not appear to be benefiting from the information as evidenced by our collective obesity rate. According to What We Eat in America, NHANES 2007-2010, over eighty percent of the population over the age of one year consumed foods outside the expected range promoted by USDA. 
Eighty percent consumed too few vegetables, seventy percent consumed too few fruits, and sixty percent consumed too much fat, sodium, and added sugars. In 20132014, over $37 \%$ of the population was obese (Fryar, Highes, Herrick, \& Ahluwali, 2018). The percent of obese individuals in the United States has been on the rise since the 1970 's. By 2007-2008, 68\% of adults were overweight or obese and 34\% were obese (Mitchell, Catenacci, Wyatt, \& Hill, 2011). Six in ten adults have at least one chronic disease, while four in ten have two or more chronic diseases (CDC, 2018). If dietary guidelines have been around for over 100 years and revised various times in order to be better understood and utilized by the general population, yet obesity and chronic disease rates continue to rise, it is important to look at whether these guidelines are user-friendly, comprehendible, and applicable to populations today. Little research has been conducted to analyze whether the MyPlate guidelines are comprehendible and if people, specifically college students, are using the guidelines when making food choices.

\section{Purpose Statement}

The purpose of this study is to analyze the knowledge and perception of MyPlate recommendations among college students and determine the difference in dietary intake between students who are familiar with MyPlate versus students who are not.

\section{Hypotheses}

$\mathrm{H}_{1}$ : As knowledge of MyPlate increases, perceived utility of MyPlate will decrease. 


\section{CHAPTER II}

\section{REVIEW OF LITERATURE}

\section{Current Dietary Trends}

Since 1980, the USDA and Department of Health and Human Services have analyzed dietary trends in Americans and published these trends, along with guidance on how Americans should be eating, as the Dietary Guidelines for Americans. This document, revised every five years, analyzes National Health and Nutrition Examination Survey (NHANES) data and creates recommendations for Americans to focus on in order to improve their nutrition and overall health. The Dietary Guidelines for Americans 2015-2020 was published in December 2015 and is based upon the NHANES data from 2007-2010. The NHANES survey found that Americans reported an inadequate consumption of recommended food groups or dietary components, while reporting overconsumption of food groups or dietary components that are recommended to be limited. Figure 1, taken from the Dietary Guidelines for Americans 2015-2020, shows Americans' reported intake patterns and their respective adherence to USDA recommendations.

This figure shows that fewer than $18 \%$ of Americans are consuming the recommended amount of vegetables and dairy and fewer than $40 \%$ of Americans are consuming enough fruit while $70 \%$ are consuming too much oil. While about half of Americans are consuming adequate amounts of grains and protein foods, it is important to note that this still means that the other $50 \%$ of the population are not (USDA, 2015). 


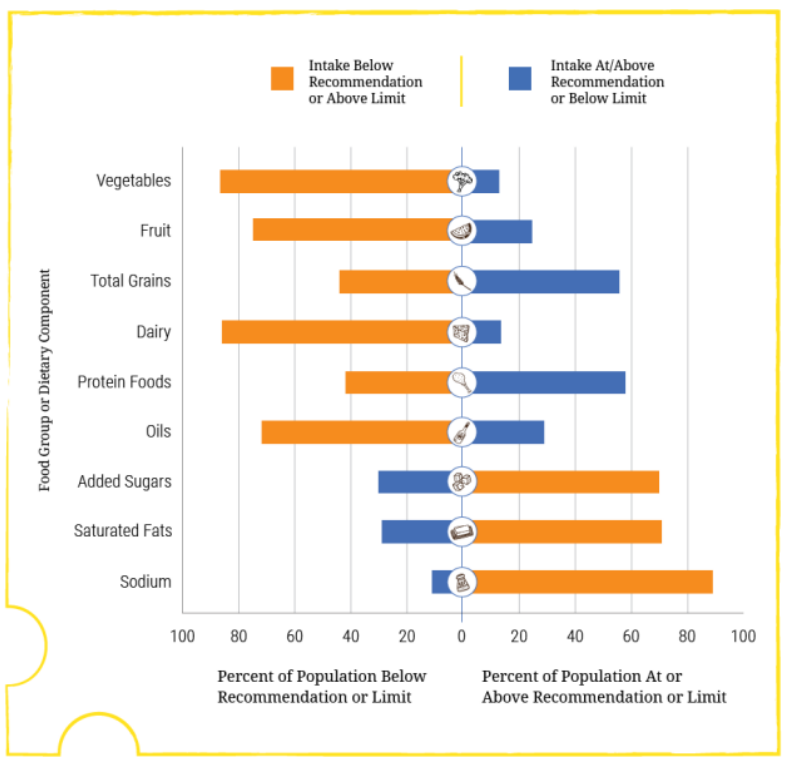

Figure 1. Dietary Intakes Compared to Recommendations/ Percent of the U.S. Population Ages 1 Year \& Older Who Are Below, At, or Above Each Dietary Goal or Limit. Graphic taken from the Dietary Guidelines for Americans 2015-2020 based on NHANES 2007-2010 intake data.

Added sugars, saturated fat, and sodium, which are linked to multiple chronic diseases when consumed in excess, appear to abundant in the current American diet (McCullough, et al., 2002; Cordain, et al., 2005; United States Department of Agriculture \& U.S. Department of Agriculture, 2015). Over 85\% of Americans consume more than the recommended amount of sodium. The Daily Value found on food labels is less than 2,300mg per day. Excess sodium intake can lead to high blood pressure, which can harm organs and arteries if it persists over time (Food and Drug Administration, 2018). Over $60 \%$ of Americans consume more than the recommended amount of added sugars and saturated fat. The American Heart Association (2018) emphasizes that high sugar intake may contribute to excess calorie intake, or majority of calories coming from low nutrient- 
dense foods, not leaving much room for essential nutrients. Excess saturated fat intake can increase LDL cholesterol and triglyceride levels. Both saturated fat and added sugars should each contribute to less than ten percent of total calories per day (USDA, 2015). According to the What We Eat in America survey by NHANES 2015-2016, adults over the age of 20 consumed about $12 \%$ of total calories from saturated fat. As of 2017, only $42 \%$ of Americans met the recommendations for sugar intake of less than $10 \%$ of calories and the average intake of sodium for Americans over the age of two exceeded 3,400mg per day (What We Eat in America, NHANES 2013-2014, 2016).

Funk and Kennedy (2016) reported that when it comes to a person's chance of living a long and healthy life, $72 \%$ of Americans indicated that it is "very important" to have healthy eating habits, $71 \%$ indicated that it is "very important" to get enough physical activity, and only $47 \%$ indicated that genetics and hereditary factors are "very important." Not only did people voice their belief in the importance of healthy eating, but $54 \%$ of American adults reported they pay more attention to eating healthy foods now than they did twenty years ago. At the same time, however, 54\% of American adults believed that eating habits were less healthy than they were twenty years ago. It appears that both quality and quantity of Americans' food consumption habits are believed to be primary causes of poor health in our modern society. This Pew Research Center Survey also found a divide between knowledge and practice. Although Americans believe eating healthy is very important in living a long healthy life, $58 \%$ of U.S. adults believe they should be eating healthier on most days, and $86 \%$ indicated that "my main focus is on eating healthy and nutritious" does not describe them at all (Funk \& Kennedy, 2016). 
Americans seem to be conflicted between what they believe is the overall trend in the American and how they view their own eating habits.

\section{Preparing Food at Home}

Preparing food at home as been linked to improved dietary intake (Zong, Eisenberg, Hu, \& Sun, 2016; Mills, Brown, Wrieden, White, \& Adams, 2017; Larson, Perry, Story, \& Neumark-Stzainer, 2006). Research has been conducted to look at the frequency of home-cooked meals based upon data from NHANES and The American Time Use Survey over the past several decades (Smith, Ng, \& Popkin, 2013; Taillie, 2018). According to (Smith, Ng, \& Popkin, 2013), energy intake from home-source food decreased $24.5 \%$ in males and $23.9 \%$ in females from 1965-1966 and 2007-2008. Fewer people cooked in 2007-2008 compared to 1965-1966; but the biggest decline was amongst low income groups. US adults maintained a relatively stable pattern of two thirds of daily energy coming from home sources and one third coming from outside of the home between the 1990's and early 2000's. According to more recent data from (Taillie, 2018), cooking at home increased from 2003 to 2016. In $200335 \%$ of men and $67 \%$ of women cooked; and in $2016,45 \%$ of men and $70 \%$ of women cooked. This data, however, is based upon respondent's answers about activities done in the past 24 hours and not based on long-term trends. With higher intake of meals prepared at home being linked to overall healthier eating patterns (Monsivais, Aggarwal, \& Drewnowski, 2014), our societal drift over the past few decades towards increased eating outside the home may help justify the decrease in healthy eating patterns (U.S. Department of Health and Human Services \& U.S. Department of Agriculture, 2015). 
In a (2006) study by Larson, Perry, Story, \& Neumark-Sztainer, higher frequency of home cooked meals was associated with closer adherence to dietary objectives from Healthy People 2010. People who consumed more home cooked meals had a higher intake of fruits and vegetables and were less likely to have an overweight BMI, excess body fat, high risk cholesterol ratio, or be at risk of developing diabetes. (Mills, Brown, Wrieden, White, \& Adams, 2017). Similarly, Zong, Eisenberg, Hi, \& Sun (2016), found that higher frequency of home-cooked meals was inversely associated with type 2 diabetes risk.

Preparing food at home is associated with improved diet quality in young adults due to the high intake of sodium, saturated fat, and sugar associated in higher quantities with eating away from home (Larson, Perry, Story, \& Neumark-Stzainer, 2006). Pelletier and Laska (2013) found that students who brought food from home had a lower consumption of fat and added sugar and a higher consumption of fruits, vegetables, fiber, dairy, and calcium. This study also found that students who consumed fast food three or more times per week, and students who frequently purchased food in the campus area had a higher intake of fat and added sugar. According to What We Eat in America, NHANES $2015-2016,66 \%$ of individuals over the age of 20 consumed about one third of total calories, added sugar, and fat from fast food restaurants. A (2006) study of young adults aged 18-23 found that some barriers to preparing meals at home include lack of cooking skills, money, appliances, time, and access to grocery stores. They found about $18 \%$ of all participants reported having very inadequate/ inadequate cooking skills, and $24.8 \%$ of all participants reported money to buy food was very inadequate/inadequate. Out of 755 
males, about $20 \%(n=153)$ indicated that they never purchased fresh vegetables; and out of 938 females, about 7\% $(n=68)$ never purchased fresh vegetables (Larson, Perry, Story, \& Neumark-Stzainer, 2006). This study found that students who participated in food preparation were more likely to meet the dietary objectives of Healthy People 2010 and were less likely to use fast food.

\section{Consuming Food Outside of the Home}

Fast food consumption and full-service restaurant consumption did not vary greatly when looking at content of total calories, total fat, and saturated fat according to An (2016). While eating at home is associated with increased fruit and vegetable consumption, meals consumed outside of the home are associated with an increase in total energy, total fat, saturated fat, cholesterol, and sodium (An, 2016). A 2018 study found that BMI was positively associated with frequency of both fast food restaurant eating and full-service restaurant eating (Bhutani, Schoeller, Walsh, \& McWilliams, 2018). Fast food has been specifically associated with higher sugar intake while fullservice restaurant food was not (An, 2016). Fast food restaurants were associated with a decreased intake of vitamin A, D, C, K, copper, and magnesium. Full-service restaurants were associated with higher intake of omega-3, B6, vitamin E, vitamin K, copper, potassium, and zinc. Anderson (2011) found that the odds of being obese were $50 \%$ higher in individuals who consumed fast food two or more times per week when compared to those who consumed fast food less than one time per week. According to the National Health and Nutrition Examination Survey, as of 2018, 37\% of U.S. adults were consuming fast food on any given day, with a majority of those adults being 
between the ages of 20-39 (Fryar, Highes, Herrick, \& Ahluwali, 2018). Between 20152016, individuals ages 20 and over consumed about 15\% of calories from fast food restaurants, and 10\% from full-service restaurants. This survey also found that adults typically consumed fast food at lunch or dinner as opposed to at breakfast or for snacks. Studies that look at food consumed away from home but excluding fast food also see a positive association between food eaten and BMI (Bezerra, Curioni, \& Sichieri, 2012). All of this data brings about the questions of whether the general public understands the nutrient content of their foods, or whether they are aware of what they should be looking for when choosing foods. According to a 2011 survey, only $16 \%$ of respondents reported using nutritional information when ordering at a fast-food restaurant (Anderson, Rafferty, Lyon-Callo, Fussman, \& Imes, 2011).

\section{Meals, Snacks, and Eating Frequency}

Eating sessions are broken down into two categories: a snack or a meal. What an individual categorizes their current eating session as may impact their food choices. According to (Bellisle, 2014), researchers suggest that snacking has been a major contributor to the rise in overweight and obesity. Between the late seventies into 20072008 , the number of adults that snacked rose from $59 \%$ to $90 \%$ (Mattes, 2014). As of 2014 , roughly $30 \%$ of the population was consuming $30 \%$ or more of their energy from snacks. Snacks can serve as a means of boosting energy and reducing hunger throughout the day or for entertainment and pleasure (Layman, 2014). Definitions of snacks and meals vary based upon the time of day, the type of food consumed, the amount of food consumed, and/or location of food consumed (Hess, Jonnalagadda, \& Slavin, 2016). 
Duffey, Pereira, \& Popkin (2013) defined snacking based upon the time of day and the size of the snack. (Lipoeto, Lin, \& Angeles-Agdeppa, 2012) defined snacks based upon the type of food being eating, and (Johnson \& Anderson, 2010) define snacking based upon time of day and amount consumed.

Raynor, Goff, Poole, and Gen (2015) point out that eating frequency is often associated with improved weight management and challenge this idea in their systematic review in which aggregate data suggested that there may not be a consensus of evidence to support increased eating frequency as having a benefit on energy intake or anthropometric measurements. Over half of the studies in this systematic review found no significant difference between energy intake or anthropometric measures amongst various eating frequencies. However, there may be some nutrient-related benefits seen with higher eating frequency. Increased eating frequency was positively associated with intake of folic acid, vitamin C, calcium, magnesium, iron, potassium, and dietary, and reduced intake of cholesterol and sodium. Individuals who reported skipping a meal and instead consuming more snacks were more likely to have less healthful intake when compared to those who ate three meals per day. Those who skipped breakfast had the lowest intake of micronutrients. Those who consumed three meals plus 2 or more snacks, had the highest intake of micronutrients. This particular eating style was associated with white middle-aged middle-class women with higher education and income (Kerver, Yang, Obayashi, Bianchi, \& Song, 2006).

These results suggest that certain eating patterns may be associated with better nutrient intake. The results do not show whether certain eating patterns are specific to 
people trying to eat more healthful. That specific data was not looked at in this study (Kerver, Yang, Obayashi, Bianchi, \& Song, 2006). Health outcomes related to snacking may differ based upon the context in which the snacking is done. Snack food is often associated as foods high in fat and carbohydrates, and low in protein and micronutrients (Layman, 2014; Bellisle, 2014). Snacking is not detrimental to health outcomes when individuals are snacking at regular times, in response to hunger, on carbohydrate-rich, low-fat foods. However, snacking based upon environmental stimuli without hunger, specifically when watching TV, may contribute to weight gain and derail weight loss progress (Bellisle, 2014). Therefore, the effects of snacking on health outcomes depends upon the context in which the snacking is done. When considering the effects of eating on overweight and obesity, it is important to consider overall eating patterns which include frequency, volume, and food quality (Mattes, 2014).

\section{Health Implications Related to Diet}

An individual's lifestyle can have a heavy impact on their overall health. Diet along with other lifestyle factors can impact weight regulation as well as cardiometabolic risk factors including blood pressure, glucose-insulin homeostasis, inflammation, metabolic expenditure, and lipoprotein concentrations (Mozaffarian, 2016). Certain foods such as non-starchy vegetables, fruits, nuts, yogurt, fish, and whole grains appear to protect against weight gain and are often recommended to prevent or treat certain chronic diseases. Understanding how one's lifestyle can impact their risk of overweight, obesity, or chronic disease development, may help prevent or treat these conditions later on in life. 


\section{Obesity}

The World Health Organization (WHO) defines overweight and obesity as "abnormal or excessive fat accumulation that presents a risk to health" (World Health Organization, 2018). A body mass index (BMI) of 25 or higher is classified as "overweight;" and a BMI of 30 or higher is classified as "obese." BMI is an individual's weight in kilograms divided by their height in meters squared. According to the Center for Disease Control (CDC), BMI is used as a screening tool due to its correlation with more direct measures of body fat as well as metabolic disease outcomes. Measuring BMI only requires height and weight which makes it an easy tool for any health professionals to use (Centers for Disease Control and Prevention, 2017). Overweight and obesity is a prominent social issue due to its increasing prevalence and correlation with increased disease risk.

Prevalence. In 2006, obese individuals had per capita medical spending that was $42 \%$ higher than normal weight individuals (Finkelstein, Trogdon, Cohen, \& Dietz, 2009). In 2015-2016, the prevalence of obesity among adults twenty years and older was $39.6 \%$. Obesity rates were highest, specifically, in adults between 40-59 years old (Hales, Carroll, Fryar, \& Ogden, 2017). Over the past three decades, as shown in Table 1, overweight and obesity trends have continued to rise. Although rates of overweight individuals began to plateau around 2009-2010, rates of obesity and extreme obesity continued to rise. 
Table 1.

Increasing BMI and obesity trends among adults 20 years and older from 1988-1994 through 2014.

Data taken from NCHS Data Brief, October 2017

\begin{tabular}{|c|c|c|c|c|c|c|c|c|c|}
\hline $\begin{array}{c}\text { Sample Size } \\
\text { and Weight } \\
\text { Status }\end{array}$ & $\begin{array}{c}\text { NHANES } \\
1988-1994\end{array}$ & $\begin{array}{c}\text { NHANES } \\
1999-2000\end{array}$ & $\begin{array}{c}\text { NHANES } \\
2001- \\
2002\end{array}$ & $\begin{array}{c}\text { NHANES } \\
2003- \\
2004\end{array}$ & $\begin{array}{c}\text { NHANES } \\
2005- \\
2006\end{array}$ & $\begin{array}{c}\text { NHANES } \\
2007- \\
2008\end{array}$ & $\begin{array}{c}\text { NHANES } \\
2009- \\
2010\end{array}$ & $\begin{array}{c}\text { NHANES } \\
2011- \\
2012\end{array}$ & $\begin{array}{c}\text { NHANES } \\
2013- \\
2014\end{array}$ \\
\hline Sample (n) & 16,679 & 4,117 & 4,413 & 4,431 & 4,356 & 5,555 & 5,926 & 5,181 & 5,455 \\
\hline $\begin{array}{c}\text { Overweight } \\
25>=\text { BMI } \\
<30\end{array}$ & 33.1 & 34.0 & 35.1 & 34.1 & 32.7 & 34.2 & 33.0 & 33.6 & 32.5 \\
\hline $\begin{array}{c}\text { Obese (BMI } \\
>30 \text { ) }\end{array}$ & 22.9 & 30.5 & 30.6 & 32.2 & 34.3 & 33.8 & 35.7 & 34.9 & 37.7 \\
\hline $\begin{array}{c}\text { Extremely } \\
\text { Obese (BMI } \\
>>=40)\end{array}$ & 2.9 & 4.7 & 5.1 & 4.8 & 5.9 & 5.7 & 6.3 & 6.4 & 7.7 \\
\hline
\end{tabular}

Causes of Obesity. Obesity is a complex combination of genes, environmental factors, and behavior (Yang, Kelly, \& He, 2008) (Hruby \& Hu, 2015). Research has shown that obesity is caused by an imbalance of calories expended versus calories consumed. An individual being in a calorie surplus; or consuming more calories than what they are burning throughout the day, will result in weight gain. Cordain (2005), in her history of the American diet, describes pre-industrial meals as minimally processed and highly reliant on home grown produce. As of 2005, foods that would not have been around prior to agriculture, such as dairy products, cereals, refined sugars, refined vegetable oils, and alcohol, made up $72.1 \%$ of the American diet.

Food Processing. Upon the industrial revolution, food processing and extended shelf-life products began to make up much of the American diet. Processing allowed for the mass production and access to foods in low-income countries and regions who may not have had easy access previously. While this was a positive change in those regions, it allowed for easy access to nutrient-poor foods for everyone else as well (World Cancer 
Research Fund \& American Institute for Cancer Research, 2007). Food processing techniques allowed for the refinement of grains and vegetable oils, leaving highly processed foods with little to no nutritional value. Adherence to a Western dietary pattern is associated with weight gain (Hruby, et al., 2016). This dietary pattern is characterized by a high intake of refined grains, sugar, saturated fat, and sodium. These nutrients continue to be consumed in high quantities despite the effort of the USDA to decrease consumer consumption (Dietary Guidelines for Americans, 2015). High fructose corn syrup is one of the refined sugars that emerged from these food processing techniques.

High fructose corn syrup (HFCS) was introduced to the food supply in the 1970's. It was economically feasible to produce in mass quantities due to chromatographic fructose enrichment technology (Cordain, et al., 2005). HFCS is a stable product that is derived from corn which is abundant and renewable, keeping price and availability stable (White, 2008). Because of this, HFCS has been widely accepted in the food industry, specifically in sugar-sweetened beverages such as soda and juice. As of 2014, most beverages in the United States were sweetened with HFCS, which has been argued as being a contributing factor to the rising obesity epidemic (Bray, Nielsen, \& Popkin, 2004). Despite being described as "high fructose," HFCS is not much different than sucrose. There are two popular HFCS products, one of which is $42 \%$ fructose, the other of which is $55 \%$ fructose. The remaining sugar is free glucose and minor amounts of bound glucose. Similarly, sucrose is $50 \%$ fructose and $50 \%$ glucose (White, 2008). Between 1960 and 2000, the intake of HFCS and the obesity epidemic were both on the 
rise. However, in 2002 as obesity continued to rise, the intake of calories from HFCS remained stagnant and even began to decline (White, 2008). Although HFCS independently may not necessarily promote obesity more so than any other sugar, beverages that are sweetened with HFCS provide little to no nutritional value and should be advised against (Malik, Schulze, \& Hu, 2006).

Sugar sweetened beverages (SSBs) only contributed to $2.5 \%$ of total energy in 1965, however by $2007-2008$, they contributed to $6.6 \%$ of energy (Welsh, Lundeen, \& Stein, 2013). SSBs include soft drinks, fruit drinks, sweetened coffee/tea, sports and energy drinks. According to data from the Nurse's Health Study II from 1991-1999, women who increased their sugar-sweetened soft drink intake from less than one per week to more than one per day had an increase in their reported total energy intake by 358kcal/day (Schulze, Manson, \& Ludwig, 2004). Women who increased their intake from low to high also had a significant increase in weight and BMI when compared to women who maintained either a low or high intake or reduced their intake. Liquid foods have low satiety and therefore although individuals are consuming more calories from SSBs, food intake may not be reduced to counteract those excess calories (Schulze, Manson, \& Ludwig, 2004; Popkin, et al., 2006). Greater sugar-sweetened soft drink and fruit punch consumption were both associated with an increased risk of type 2 diabetes. Between 1990 -2010, total intake of SSBs and soda intake decreased (Kit, Fakhouri, Park, Nielsen, \& Ogden, 2013)

Nutrient intake. Total fat intake, once believed a primary factor of weight gain, has recently been re-evaluated. According to data from the Nurse's Health Study (NHS), 
total fat and unsaturated fat intake was not seen to be strongly associated with weight gain, while saturated and trans fats were (Hruby, et al., 2016). When looking at low fat diets versus low carbohydrate diets for weight loss, it does not appear that one is more beneficial than the other. Rather, energy intake is the primary contributing factor in the relationship between diet and weight (Wadden, Webb, Moran, \& Bailer, 2012). Energy or calorie restriction has been a primary focus when it comes to weight loss strategies. Research has shown that a diet that restricts caloric intake is associated with better weight outcomes even if the diet itself is low quality. However, when it comes to long term weight loss maintenance, a healthier diet is more effective (Hruby \& Hu, 2015). Data also indicated that women who consumed more whole grains gained less weight than women who consumed more refined grains (Hruby, et al., 2016).

Physical activity. Physical activity has also shown to play a large role in the promotion and prevention of weight gain and obesity. Sedentary activities that require sitting relatively motionless for extended periods of time, such as watching TV or working at a computer, are associated with increased weight gain. Increasing physical activity levels may lower the risk of weight gain and obesity (Hruby, et al., 2016). Physical activity may decrease the risk of chronic diseases independent of weight status and that individuals should focus on health rather than weight (Bombak, 2014). However, according to 2013 data analyzed by NHANES, only about $20 \%$ of all adults met physical activity guidelines, majority of those adults between ages 18-24 (Dietary Guidelines for Americans, 2015). 
In the mid-20th century, the United States saw a direct link between wealth and obesity- those who were wealthier were more likely to be obese. Inversely, with a rise in cheap nutrient-poor processed foods, there has now been a flip and wealth has become indirectly associated with obesity, along with education (Hruby, et al., 2016) (Pantalone, et al., 2017). Obesity is multi-factorial including genetics, socioeconomic status, calorie consumption, physical activity, and various environmental factors. While not every risk factor is modifiable, controlling the ones that are may help decrease risk of obesity.

\section{Chronic Diseases}

Half of American adults have one or more preventable chronic diseases, most of which are associated with poor dietary habits and lack of physical activity (Dietary Guidelines for Americans, 2015). Food processing techniques have resulted in a shift in American dietary habits over the past several decades. The refinement of grains and sugars create a carbohydrate that is low in fiber and has a "high glycemic index." Consumption of high glycemic foods results in a rapid spike of blood sugars and in turn, insulin. Long-term high intake of high glycemic foods may lead to hyperglycemia, hyperinsulinemia which can eventually lead to insulin resistance. Other diseases related to hyperinsulinemia include obesity, coronary heart disease, type 2 diabetes, hypertension, and dyslipidemia (Cordain, et al., 2005). The processing of oils has led to the increased consumption of saturated and trans fatty acids, which have been associated with an increased risk of cardiovascular disease (Cordain, et al., 2005). A high intake of saturated and trans fatty acids may lead to arrhythmias, blood clotting, plaque build-up, increased triglycerides in the blood and increased blood pressure. 
The presence of one chronic disease may also increase the risk of developing other chronic diseases. Diabetes alone increases the risk of cardiovascular disease, hypertension, and dyslipidemia, and some cancers (Pantalone, et al., 2017) (Hruby \& Hu, 2015). Cordain et. al, (2005) summarizes the risk of chronic diseases based upon foods consumed and boils it down into seven categories; glycemic load, fatty acid composition, macronutrient composition, micronutrient density, acid-base balance, sodium-potassium ratio, and fiber content. She notes that the issue is that we are currently consuming foods that our genome is not accustomed to. Literature also suggests that obesity plays a role in the prevalence of chronic disease. Research has shown that as much as a $5-10 \%$ reduction in weight may improve insulin sensitivity, cardiovascular disease risk, sleep apnea, and depression (Pantalone, et al., 2017).

Cardiovascular disease. According to the American Heart Association (2017), cardiovascular disease (CVD) is a term that encompasses multiple diseases including coronary heart disease, hypertension, heart attack, arrhythmia, heart failure, heart valve problems, and stroke. Many of these conditions are related to atherosclerosis, which is the narrowing of blood vessels (American Heart Association, 2017). Blood vessels can narrow due to plaque build-up as a response to inflammation in the body (Mahan, EscottStump, \& Raymond, 2012). As the plaque enlarges it impedes blood flow which may progress to clot formation (Gropper \& Smith, 2013). When blood flow is restricted, surrounding tissues cannot receive adequate oxygen supply and can die as a result (Gropper \& Smith, 2013). 
Prevalence. CVD was considered to be a common cause of death in developed nations by the $20^{\text {th }}$ century. Today, it is one of the leading causes of death in the United States, responsible for about one in every four deaths (CDC.gov, 2017). This rise in CVD has been attributed to a rise in cigarette smoking in the 1960's, an increase in consumption of processed foods, and a decrease in physical activity due to Americans having access to automobiles (Dalen, Alpert, Goldberg, \& Weinstein, 2014). It is important to note that heart attacks were first diagnosed in 1912 and the subsequent increases in the sensitivity and specificity of medical technology has led to the ability to detect a myocardial infarction earlier and more accurately. (Dalen, Alpert, Goldberg, \& Weinstein, 2014). Between 2013-2016, 121.5 million American adults had some form of CVD (American Heart Association, 2019). Cardiovascular disease remains the underlying cause of death in nearly one in three deaths in the United States (Benjamin, et al., 2018).

Risk factors. Risk factors for heart disease include unhealthy diet, physical inactivity, tobacco use, and harmful alcohol use (Benjamin, et al., 2018). These behaviors, individually or combined, can increase risk of high blood sugar, high blood lipid levels, high blood pressure/hypertension, and overweight and obesity which are all associated with an increased risk of heart attack, stroke, heart failure and other complications (World Health Organization, 2017). In 2014, 27\% of adults had hypertension, and $21.6 \%$ of adults had lipid disorders, both of which are heavily associated with heart disease. Many of the risk factors associated with medical conditions that may result in cardiovascular disease are modifiable risk factors, meaning 
the risk can be decreased based upon individual behavior. These modifiable risk factors include unhealthy diet, physical inactivity, harmful alcohol use, and smoking.

Although tobacco use has been on the decline, it is still the leading cause of preventable death in the United States and across the world (American Heart Association, 2018). Smoking is attributed to more than 480,000 deaths per year. In 2017 , an estimated $14 \%$ of adults age 18 and older currently smoked cigarettes (Centers for Disease Control and Prevention, 2019). There are various mechanisms by which smoking can lead to cardiovascular disease. These include oxidative injury, endothelial damage and dysfunction, inflammation, enhanced thrombosis, hemodynamic stress, increased LDL and decreased HDL, insulin resistance and diabetes, reduced oxygen delivery, and arrhythmogenesis (Benowitz \& Burbank, 2016). Nicotine affects the sympathetic nervous system resulting in an increased heart rate, blood pressure, and myocardial contractility. This results in an increased demand for oxygen and nutrients. However, at the same time oxidant chemicals and carbon monoxide are causing a decrease in oxygen availability and an increase in inflammation which results in reduced blood, oxygen, and nutrient supply to the heart. This combination can lead to myocardial ischemia and/or myocardial infarction (Benowitz \& Burbank, 2016).

Physical activity. Physical activity has long been looked at for its effects on cardiovascular health. Current guidelines suggest 150 minutes per week at minimum for adults seeking substantial health benefits. For extensive health benefits, adults should participate in up to 300 minutes of aerobic activity per week (Centers for Disease Control and Prevention, 2016). According to an (2016) overview, physical activity can help 
prevent the development of hypertension, hypercholesterolemia, metabolic syndrome, and diabetes, all of which are associated with an increased risk of CVD. Those who participate in regular physical activity may see a reduction in blood pressure, inflammatory biomarkers, and arterial stiffness. Walking three or more hours a week alone is associated with a $35 \%$ decreased risk of coronary events compared to those who walk infrequently (Alves, et al., 2016). According to the 2015 National Health Interview Survey, only $21.5 \%$ of American adults and only $27.1 \%$ of adolescents reported adequate participation in aerobic and muscle-training activities (American Heart Association, 2018).

Dietary implications. Diet also plays a large role in the risk and prevention of cardiovascular disease. Following the Industrial Revolution, hydrogenation became a popular food process technique. The process of hydrogenation changes the structure of polyunsaturated fatty acids converting them from a liquid to a solid at room temperature, which improves stability and flavor. Hydrogenated oils were often found in foods such as cakes, pies, cookies, crackers, rolls, mayonnaise, and potato chips (Emken, 1984). This resulted in high intake of fat, specifically trans and saturated fat. Trans fat may increase systemic inflammation, a decrease in high-density lipoprotein (HDL), and an increase in low-density lipoprotein (LDL) (Gropper \& Smith, 2013), which increases risk for CVD. HDL is often referred to as "good" cholesterol, while LDL is referred to as "bad" cholesterol. This is due to the notion that HDL to LDL ratio promotes "wellness" (Gropper \& Smith, 2013). The American Heart Association recommends consuming as little trans-fat as possible (American Heart Association, 2017). A Western diet, which 
includes red and processed meats, refined grains, high sodium, and high-fat dairy products is considered "unhealthy" as high intake of each of these individual food groups is associated with poor health outcomes (Grosso, et al., 2017)(World Cancer Research Fund \& American Institute for Cancer Research, 2007).

Intake of fruits, vegetables, beans/legumes, nuts/seeds, and whole grains have been associated with a decreased risk of heart disease, stroke, and diabetes (Micha, et al., 2017). Recent studies have shown seafood and omega-3s were linked to a lower risk of CVD and yogurt was associated with a decreased risk of diabetes (Micha, et al., 2017). When discussing the relationship between food and chronic disease, it is important to note the individual nutrients in those foods that play a role as well. Saturated and trans fatty acids may increase the risk of cardiovascular disease due to their effect on raising low-density lipoprotein (LDL) cholesterol. High LDL levels has been associated with atherosclerosis, a risk factor for CVD. Intake of monounsaturated and polyunsaturated fatty acids may help reduce risk of CVD due to their anti-inflammatory effects as well as their ability to help reduce LDL cholesterol while maintaining or slightly raising HDL cholesterol.

The Mediterranean diet has been highly recommended for individuals at risk of or diagnosed with CVD because it may decrease recurrent CVD by $50-70 \%$. The focus of this dietary pattern is similar to other recommended diets in that it focuses on intake of fruits, vegetables, whole grains, beans, legumes, and seeds. These foods are particularly high in fiber which has been found to be protective against CVD. Fiber can be found in two forms; soluble and insoluble; and soluble fiber, in particular, can help lower 
cholesterol (Gropper \& Smith, 2013) (Mahan, Escott-Stump, \& Raymond, 2012). Diets rich in fiber have also been associated with lower blood pressure as well as improved glycemic control (Gropper \& Smith, 2013). The Mediterranean diet also puts an emphasis, specifically, on olive oil, which is a monounsaturated fatty acid, as well as seafood (Mahan, Escott-Stump, \& Raymond, 2012). In a randomized control trial, researchers found that participants who followed a Mediterranean diet supplemented with either olive oil or nuts had a significant reduction in the risk of cardiovascular events among high risk individuals (Estruch, et al., 2013).

Diabetes. Diabetes is a disease in which an individual's blood glucose, also known as blood sugar, is too high (National Institute of Diabetes and Digestive and Kidney Diseases, 2016). Type I diabetes is typically either idiopathic or immunemediated and is not the result of lifestyle factors. Type II diabetes, however, is due to genetic, lifestyle, and environmental factors (Mahan, Escott-Stump, \& Raymond, 2012). Type II diabetes is characterized by a combination of insulin resistance and beta-cell dysfunction. Beta cells are responsible for the production of insulin.

Prolonged high intake of high glycemic foods may lead to hyperglycemia or hyperinsulinemia (Shanik, et al., 2008) which can eventually lead to insulin resistance. Hyperglycemia is high blood sugar, and hyperinsulinemia is high insulin levels relative to the amount of glucose in the blood. High blood sugars promote extra insulin secretion from beta cells. This increase in insulin causes the downregulation of insulin receptors, leading to insulin resistance (Tripathi, et. al, 2006). In individual's with type II diabetes, receptors are resistant to insulin and therefore glucose cannot be absorbed into the cell. 
This results in elevated blood sugars and eventually the diagnosis of type II diabetes (Mahan, Escott-Stump, \& Raymond, 2012); (Gropper \& Smith, 2013). Hyperglycemia, excessive thirst (polydipsia), frequent urination (polyuria), and fatigue are all symptoms of uncontrolled diabetes. If diabetes goes untreated, it can lead to cardiovascular disease, neuropathy, retinopathy and ketoacidosis.

Prevalence. Diabetes in the seventh leading cause of death in the United States (American Diabetes Association, 2018). As of 2017, 30.3 million Americans were diagnosed with diabetes, and 84.1 million Americans 18 and over were diagnosed with prediabetes (Center of Disease Control and Prevention, 2018). Prevalence appears to be found in American Indians/Alaskan Native, Blacks, and Hispanics. There are various types of diabetes, however type II is the most common, accounting for $90-95 \%$ of diabetes cases (National Institute of Diabetes and Digestive and Kidney Diseases, 2017) (Mahan, Escott-Stump, \& Raymond, 2012). Type II diabetes can be developed at any age but has traditionally occurred more often in middle-aged and older adults ( $>45$ years old). However, between 1990 and 1998, the prevalence of diabetes increased nearly $76 \%$ among people in their thirties (Mahan, Escott-Stump, \& Raymond, 2012). Rates of type II diabetes in children ages 10-19 rose 21\% between 2001-2009 (Gebel, 2012). The development of type 2 diabetes can be the result of various risk factors, yet diagnosis criteria is consistent for all ages and gender.

Risk factors and diagnosis. Genetics, age, ethnicity, and history of gestational diabetes all impose a risk in the development of type II diabetes; however, modifiable lifestyle factors are heavy influencers as well. These factors include obesity, intake of 
excessive calories and lack of physical activity, smoking, and alcohol consumption (Mahan, Escott-Stump, \& Raymond, 2012). As noted earlier on, obesity is the effect of an energy imbalance. The combination of a sedentary lifestyle and chronic overeating lead to a low energy output compared to energy intake (Mahan, Escott-Stump, \& Raymond, 2012). Not only is excess body fat a risk factor for diabetes, but the distribution plays a role as well. Waist circumference or waist-to-hip ratio was found to be an independent predictor of diabetes risk (Hruby, et al., 2016). In Krause's Food and the Nutrition Care Process, a waist circumference of over 40 inches in men and over 35 inches in women indicated an increased risk (Mahan, Escott-Stump, \& Raymond, 2012). Comparatively, in a 2016 section from the Nurse's Health Study, a waist circumference of 38 or more compared to a waist circumference of 28 , increased risk by six times (Hruby, et al., 2016).

Overweight individuals who have one or more additional risk factors should be screened for diabetes (Mahan, Escott-Stump, \& Raymond, 2012). A1C, plasma glucose, and fasting plasma glucose (FPG) are measured to diagnose diabetes. A1C gives an average blood glucose level over the past three months. Fasting plasma glucose gives a measure of blood glucose at a set point in time after fasting for at least eight hours. Plasma glucose (PG) gives a measure of blood glucose levels two hours after ingesting 75 grams of carbohydrates. Table 2 provides an overview of the diagnostic criteria for diabetes and prediabetes. 
Table 2

Diagnostic Criteria for Diabetes and Prediabetes. Values taken from Krause's Food and the Nutrition Care Process.

\begin{tabular}{|l|l|l|l|}
\hline & A1C & $\begin{array}{l}\text { Fasting Plasma } \\
\text { Glucose }(\mathrm{FBG})\end{array}$ & $\begin{array}{l}\text { 2-hour Plasma } \\
\text { Glucose }(\mathrm{PG})\end{array}$ \\
\hline Diabetes & $>/=6 \%$ & $>/=126 \mathrm{mg} / \mathrm{dL}$ & $>/=200 \mathrm{mg} / \mathrm{dL}$ \\
\hline Prediabetes & $5.7-6.4 \%$ & $100-125 \mathrm{mg} / \mathrm{dL}$ & $140-199 \mathrm{mg} / \mathrm{dL}$ \\
\hline Normal & $<5.7 \%$ & $<100 \mathrm{mg} / \mathrm{dL}$ & $<140 \mathrm{mg} / \mathrm{dL}$ \\
\hline
\end{tabular}

Physical activity. Regular exercise is promoted for its effect on weight loss and maintenance as well as its effect on insulin sensitivity. Aerobic exercise can improve insulin sensitivity up to 72 hours (Sigal, Kenny, Wasserman, Castaneda-Sceppa, \& White, Physical activity/exercise and type 2 diabetes, 2006). Individuals with type 2 diabetes are recommended 150 minutes of aerobic exercise per week, over the course of at least three days, with no more than two consecutive days without physical activity (Mahan, Escott-Stump, \& Raymond, 2012). Resistance training can also improve insulin sensitivity due to increased muscle mass which has shown to improve glycemic control (Maiorana, O'Driscoll, Goodman, Taylor, \& Green, 2002). According to the American Diabetes Association (ADA), individuals who also experience a diet and exerciseinduced weight loss of five to seven percent, have a reduced progression from impaired glucose tolerance into type 2 diabetes (Sigal, Kenny, Wasserman, Castaneda-Sceppa, \& White, Physical activity/exercise and type 2 diabetes, 2006).

Dietary implications. While the management of type 2 diabetes often involves medication, diet and exercise play a primary role. The goal of medical nutrition therapy 
is to improve glucose control, lipid and lipoprotein profiles, and blood pressure (Mahan, Escott-Stump, \& Raymond, 2012). A registered dietitian typically encourages an intake based upon the dietary reference intakes (DRI's) for healthy eating. Total calories should be comprised of $45-60 \%$ from carbohydrates, $20-35 \%$ from fats, and $10-35 \%$ from protein (Mahan, Escott-Stump, \& Raymond, 2012). Carbohydrate intake is particularly important for patients with type 2 diabetes. There is not one specific amount of carbohydrates that is recommended for those with type 2 diabetes, however, a consistent intake of low glycemic foods that are high in fiber is encouraged. Majority of carbohydrates should come from fruits, vegetables, whole grains, legumes, and low-fat milk (American Diabetes Association, 2008). Certain foods such as nuts and seeds, whole grains, yogurt, and fiber have shown protective effects against diabetes. Patients are encouraged to set fiber intake goals at 14 grams per 1,000 kilocalories, with an emphasis on soluble fiber (Mahan, Escott-Stump, \& Raymond, 2012) (American Diabetes Association, 2008).

Overall, the goal is for patients to have a consistent carbohydrate intake from day to day in order to improve glycemic control (Mahan, Escott-Stump, \& Raymond, 2012). This is typically achieved through carbohydrate counting. One serving of carbohydrates, regardless of the source, is 15 grams of carbohydrates. The food exchange list groups foods into various categories including non-starchy vegetables, starches, fruits, milk, desserts, protein, and other carbohydrates. The food lists are grouped together so that all the foods have similar nutrition profiles, making it easy for consumers to swap one food 
for another while keeping track of carbohydrate consumption (Mahan, Escott-Stump, \& Raymond, 2012).

Diabetes alone is a risk factor for cardiovascular disease (CVD). Because of this, diet recommendations are made to reduce risk. Patients with type 2 diabetes often have elevated LDL cholesterol and triglycerides, and low HDL cholesterol levels. Saturated fat should be reduced to less than ten percent of total calories, and trans-fat should be avoided as much as possible (Evert, et al., 2013). A Mediterranean diet may be beneficial both for improving glycemic control as well as reducing risk of CVD (Evert, et al., 2013).

Cancer. Cancer is a collection of diseases that results from the abnormal growth and proliferation of cells. Some cancer cells form tissue masses called tumors, which can continue to grow and invade nearby tissues (National Cancer Institute, 2015). Any cancer-causing agent is known as a carcinogen, which typically targets DNA, often resulting in a mutation (Alberts, et al., 2002). These cellular mutations can cause the cell to respond abnormally to signaling and function irregularly. Apoptosis is the programmed death of a cell in order to keep from cell overgrowth. Cancerous cells do not respond to the signals that would normally result in apoptosis (National Cancer Institute, 2015). This is what allows cancer cells to continue to grow and migrate areas of the body other than where they formed (National Cancer Institute, 2015). There are two terms often used to describe cancer; tumors and neoplasms. A tumor means "swelling" and neoplasm means "new growth" (Zelman, Tompary, Raymond, Holdaway, \& Mulvihill, 2010). When a neoplasm is cancerous, its cells will divide rapidly and 
accumulate in normal tissue, resulting in tumor growth. The most common types of cancer in descending order include breast, lung, prostate, colon and rectum, melanoma, bladder, non-Hodgkin lymphoma, kidney and renal pelvis, endometrial, leukemia, pancreatic, thyroid, and liver (National Cancer Institute, 2018)

Prevalence. According to the National Cancer Institute (2018), there are 439.2 new cases of cancer per 100,000 men and women per year. The American Cancer Society (2019) predicted that 1,762,450 new cases of cancer will be diagnosed in 2019 which equates to more than 4,800 new cases each day. The overall death rate as a result of cancer has decreased since the 1990's and this may be due to a decrease in smoking as well as advancements in medical technology. However, the number of people with cancer, globally, has doubled since 1990 (Roser \& Ritchie, 2018). Despite the decline in death rates related to cancer, risk factors such as obesity and age continue to rise (National Cancer Institute, 2018). Majority of cancer cases occur in those over the age of 50 (Roser \& Ritchie, 2018).

Risk factors. Cancer appears to be heavily influenced by environmental and lifestyle factors (World Cancer Research Fund \& American Institute for Cancer Research, 2007). This is demonstrated by the different rates of cancer among various geographic locations, as well as the different types of cancer that are seen heavily in some groups of people while being nonexistent in other groups of people. For example, cancers in middle-income countries which are attributed to lifestyle factors such as smoking, diet, obesity, and alcohol intake include tracheal, bronchus, and lung cancer in a higher prevalence. Lower income countries have a higher prevalence of colon, rectum, 
liver, cervical, stomach, and breast cancer (Roser \& Ritchie, 2018). Differences in cancer rates among different countries, changes in migrating populations, and various changes over time indicate that cancer is heavily dependent on lifestyle and environmental factors. Some of these factors include weight, smoking, diet, and alcohol consumption (Khan, Afaq, \& Mukhtar, 2010) (World Cancer Research Fund \& American Institute for Cancer Research, 2007).

Tobacco use in long-term heavy smokers increases risk of cancer by 20 -fold; while smoking cessation can decrease cancer risk by one-third (Zelman, Tompary, Raymond, Holdaway, \& Mulvihill, 2010). Tobacco is a major risk factor for head and neck cancer as well as stomach, pancreas, kidney, bladder, and cervix. Cigarette smoke contains at least 80 known carcinogens, which all have different mechanisms for causing cancer. On top of this, cigarette smoke is a source of oxidative stress. Oxidative stress is a disturbance in the balance of free radicals and protective antioxidants and can lead to tissue damage (Betteridge, 2000). Chronically, oxidative stress may lead to DNA damage and increased risk of cancer development. Oxidative stress is not only associated with tobacco and carcinogens, but obesity as well.

Obesity has been linked to various cancers including colon, endometrium, postmenopausal breast, kidney, esophagus, pancreas, and gallbladder (Vucenik \& Stains, 2012). Various mechanisms are suggested to link obesity with increased cancer risk. Leptin, in particular, is a hormone that is typically present in high amounts in individuals with high adipose stores. It is important for appetite control and energy balance and plays a role in the association between obesity and cancer. Leptin is positively associated 
with adipose stores and may induce cancer progression through its stimulation of cell proliferation (Vucenik \& Stains, 2012) (World Cancer Research Fund \& American Institute for Cancer Research, 2007). Increased adipose tissue is also associated with increased proinflammatory cytokines (Vucenik \& Stains, 2012). Inflammation can promote the proliferation and differentiation of cells and inhibit apoptosis (World Cancer Research Fund \& American Institute for Cancer Research, 2007). Not only can obesity promote inflammation, but chronic inflammatory conditions, such as ulcerative colitis and Barrett's esophagus, can also be predicative of cancer.

Dietary implications. Diet has shown to play a key role in the development of some cancers. In a (2017) meta-analysis, healthy dietary patterns, including high fruit, vegetable, and whole grain intakes were associated with a decreased risk of mortality in cancer survivors. Similarly, Grosso et. al, (2017) systematic review found that a "healthy diet" composed of mostly fruit- and vegetable-based foods, was associated with a decreased risk of colorectal cancer when compared to a "traditional" diet composed of animal products, salty and sweet and refined foods. Adherence to a "traditional" or "western" diet was associated with an increased risk of breast, pancreatic, lung, and prostatic cancer in case-control studies (Grosso, et al., 2017). Specific nutrients found in these foods such as vitamin $\mathrm{D}$, folate, calcium, and selenium are considered protective against colorectal cancer (Mahan, Escott-Stump, \& Raymond, 2012). The World Cancer Research Fund (WCRF) and the American Institute of Cancer Research (AICR) have specific lifestyle recommendations in place with a goal of preventing cancer risk. These recommendations include: maintaining a healthy body weight, being physically active as 
a part of everyday life, limiting consumption of energy-dense foods and avoiding sugary drinks, eating mostly plant foods, limiting intake of red and processed meat, limiting alcoholic beverages, and aiming to meet nutrition needs through diet instead of supplements (American Institute for Cancer Research, 2019). Following these recommendations has shown to reduce risk of certain types of cancer (Hastert \& White, 2016; Romaguera, et al., 2012). Romaguero et al. (2012) created score categories based upon the number of WCRF/AICR recommendations individuals met. Scores were set from one to five and indicated slightly different criteria for men and women. A score of one was given to men who met zero to two of the WCRF/AICR categories; and women who met zero to three of the categories. A score of five was given to men who met five to six of the categories and to women who met six to seven of the categories. Women had an additional category due to breastfeeding recommendations. A one point increment was associated with a five percent decreased risk of developing any cancer. Overall, men with a score of five or more points, and women with a score of six or more points were $18 \%$ less likely to develop any cancer compared to those with a score of one (Romaguera, et al., 2012). Similarly, a more recent study found the benefit of following WCRF/AICR recommendations in cancer risk (Hastert \& White, 2016). Hastert and White found that meeting one to three of the recommendations was associated with a 34$45 \%$ reduced risk of colorectal cancer; and following four to six of the recommendations was associated with a 58\% reduced risk. 


\section{Dietary Guidelines and Recommendations}

Food guides are not unique to the United States, with more than 100 countries having some sort of food-based dietary guideline (Food and Agriculture Organization of the United Nations, 2018). In all cases, dietary guidelines have been created to combat acute and/or chronic undernutrition, micronutrient deficiencies, and obesity and dietrelated diseases. Some regions have very similar guidelines to the United States. The United Kingdom has the Eatwell plate that was developed in 2007. Their plate includes fruits and vegetables, protein foods, whole grains, and dairy but differs slightly from the United States in that it includes a section for oils and spreads, water, and sweets and desserts, and includes text to explain how to choose foods from each section on the plate. Canada's current food guide was just released in 2018 and depicts a plate very similar to the United States MyPlate. This replaced the image of a rainbow which was developed in 2007 and includes a section for each of the four food groups. Just like in the United States, Canada recommends making half of grain products whole grain, eating a variety of fruits and vegetables, and limiting saturated fat, sodium, and sugar. While food guides all over the world have various differences, they all have very similar messages; eat plenty of fruits, vegetables, and whole grains while avoiding excess added sugars, saturated fat, and sodium. Ratner and Riis (2014) discussed the importance of having memorable guidelines in order to communicate science-based recommendations. They indicated that in order for consumers to follow the guidelines, they must remember the guidelines. They recommend leaving details out and leaving consumers with the essence of the message. Although some detail was lost when the MyPyramid was replaced with 
the MyPlate, Ratner and Riis, (2014) believed the MyPlate would be better remembered due to the chunking of information and using a plate at a meal can serve as a trigger to remembering the MyPlate.

\section{Current Dietary Guidelines}

The United States Department of Agriculture (USDA) along with Health and Human Services (HHS) have teamed up to establish and publish the Dietary Guidelines for Americans (DGA) every five years since 1980. These guidelines reflect the advancements in scientific knowledge and translate it into nutrition guidelines in order to promote health in the United States (U.S. Department of Health and Human Services \& U.S. Department of Agriculture, 2015). The USDA and HHS first start by analyzing current data, determining what changes need to be made, and how to implement those changes through guidelines. Next, necessary revisions are made to the previous guidelines based upon current scientific findings. The public are invited to submit written or oral comments and the policy document is made and based on scientific evidence. This document is reviewed multiple times and then published as the Dietary Guidelines for Americans and includes five Guidelines along with other recommendations. The five Guidelines for 2015-2020 include; "follow a healthy eating pattern across the lifespan," "focus on variety, nutrient density, and amount," "limit calories from added sugars and saturated fats and reduce sodium intake," "shift to healthier food and beverage choices," and "support healthy eating patterns for all" (Dietary Guidelines for Americans, 2015). Implementation is the final step in the process of developing the Dietary Guidelines. It is the job of the Federal government to apply the 
Guidelines and aid consumers in making healthy decisions. Professionals are encouraged to do this through USDA's MyPlate. The MyPlate provides nutrition recommendations in a more simplistic way in order to be easily understood by consumers.

MyPlate. MyPlate, shown in Figure 1, was launched in 2011 along with the 2010 Dietary Guidelines for Americans. Prior to MyPlate, the food guide was depicted as a pyramid, shown in Figure 2, from 1992, updated once in 2005, and retired in 2011. According to a report from the Washington Post, USDA officials described the pyramid as being tired out and overly complex, with the MyPlate being created to promote a more simplistic and consumer-friendly model of the DGA (Washington Post, 2011).

Additionally, according to (Layman, 2014), the pyramid was created primarily with the intention to limit saturated fat and cholesterol. The MyPlate was created with two major changes from the pyramid; an emphasis on protein more so than carbohydrates, and a focus on balanced meals versus net daily consumption (Layman, 2014). The MyPlate depicts what a plate should look like when consumers sit down to eat. The plate is divided as follows: $30 \%$ vegetables, $20 \%$ fruits, $30 \%$ grains, and $20 \%$ protein (Federal Occupational Health, n.d.). This graphic was created to be a reminder of healthy eating, but not to provide specific messages (ChooseMyPlate, 2011). Although the MyPlate image does not provide specifics about how consumers should eat based on age, gender, and activity level, the ChooseMyPlate website is intended to provide that information through website tabs for each food group with recommended servings per day based upon age and gender. The MyPlate message was intended to promote four basic strategies to build a healthy eating style. These strategies include; focusing on variety, amount, and 
nutrition; choosing foods and beverages low in saturated fat, sodium, and added sugar; and starting with small changes to improve eating behavior, and supporting healthy eating for everyone (ChooseMyPlate, 2018). Despite initial enthusiasm from nutrition, health, and policy professionals as well as the First Lady of the United States, (Washington Post, 2011), more recent reports have indicated questions and concern from consumers and lay people about the utility of the new MyPlate model.

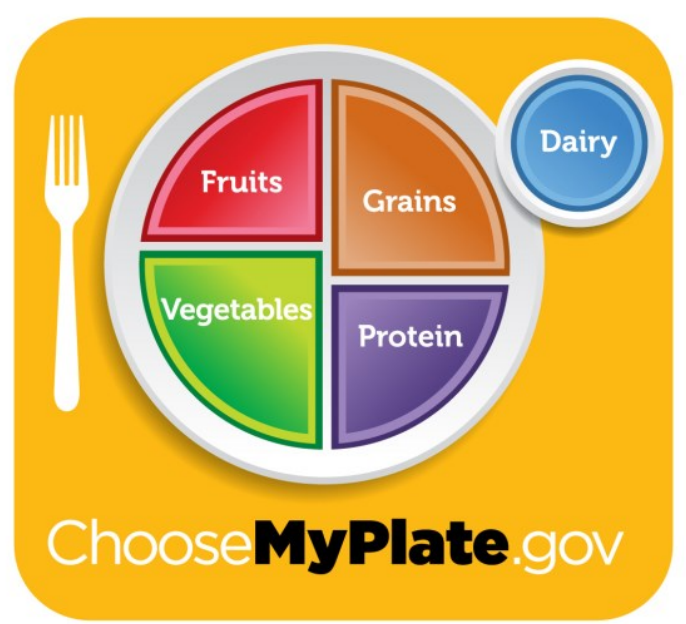

Figure 2. MyPlate graphic released in 2011 by United States Department of Agriculture (USDA). Taken from www.choosemyplate.gov. 


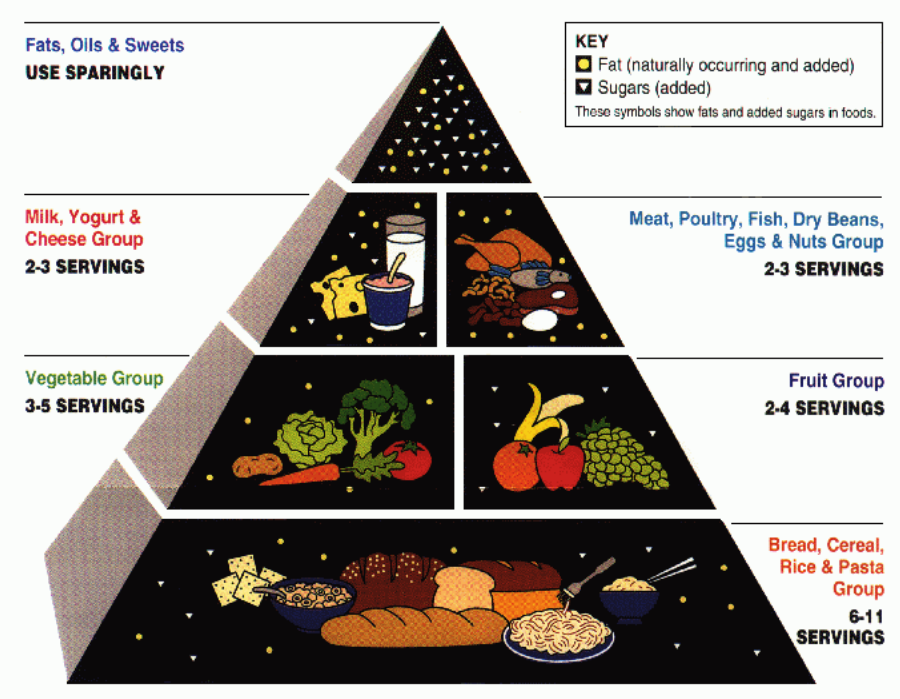

Figure 3. Food Guide Pyramid released in 1992 by United States Department of Agriculture (USDA). Taken from https://www.cnpp.usda.gov/food-guide-pyramidgraphic-resources.

Downfalls of MyPlate. A recent journal article by registered dietitians Haven and Maniscalo (2014) discussed the questions and beliefs consumers had regarding MyPlate. They broke down the information into four different "myths." These include; "all meals should be eaten on a plate," "no snacks allowed," "MyPlate is fat free," and "protein foods $=$ meat $($ Haven \& Maniscalco, 2014).” The article goes on to explain that the MyPlate is not intended to be taken literally but to serve as a reminder to make healthy, balanced meals that include all food groups. MyPlate also is not intended to force consumers to eat every food group at every meal, promote eating in a compartmentalized manner, or offer plate size recommendations (Haven \& Maniscalco, 2014). This may be confusing to consumers to get a clear message from MyPlate when it appears to be up to 
interpretation. When using plate mapping, (Sharp \& Sobal, 2012) found that college students drew larger portions when given larger plates. Although this particular study did not look at what college students actually consumed it is supported by DiSantis et al. (2013) who found that children who were given adult-size dishware and allowed to selfserve lunch served themselves also ate more than the children who were given child-size dishware and asked to serve themselves. Although MyPlate may be an effective model for promoting healthy eating patterns, if being used to copy meals from, it may influence consumers to actually consume more than what they originally would have (Sharp \& Sobal, 2012). The model also may be leaving out important healthful foods. As noted by Haven and Maniscalco (2014), fats, that are recommended by the DGA, such as oils and nuts, are not given any representation on the plate. It is up to consumers to either have been exposed to education on MyPlate, look at the website, or already have an understanding of how fats should be incorporated into a healthy diet.

Effectiveness of MyPlate. In 2017, researchers looked at NHANES data to determine the reach of MyPlate. They found that about 25\% of adolescents age 16-19 were familiar with MyPlate; and less than 20\% of adults 20-29 were familiar. It is not surprising that the adolescent age group were more familiar with MyPlate given that one of the avenues in which the icon is shared is in school classrooms and cafeterias (Tagtow \& Raghavan, 2017). The MyPlate website includes toolkits for teachers to utilize with students between the ages of two to eleven. Based upon that age group, students who would have been ages two to eleven and been exposed to MyPlate in schools back in 2011would currently be 10-19 years old. Beyond that, resources are available for 
consumers and healthcare professionals with no data on how often those resources are being used (ChooseMyPlate, 2018). The 2018 Food and Health Survey conducted by the International Food Information Council Foundation compared current eating patterns to those recommended by MyPlate. They asked 1,009 individuals "how familiar are you, if at all, with the following graphic?" Just over ten percent indicated they have seen it and know a lot about it, which was less than in 2017 . Over $30 \%$ indicated they had never seen it before, which was up from 2017. Aside from NHANES and International Food Information Council Foundation, there is little research looking at how MyPlate is being used and whether the information is effective in promoting a healthy eating style.

\section{College Students}

College is a time where many students are living away from home and are presented many different food choices. Factors that influence eating behavior were broken down into five different categories by Deliens, Clarys, Bourdeaudhuij, \& Deforche (2014). These categories include social environment, physical environment, macro environment, university characteristics, and individual. Arnett (2000) describes the transition period from late teens through twenties "emerging adulthood" which is a time of profound change. Most teens leave home by 18-19 years old, but have varying living situations. Some teens attend college and could live in a dorm, independently, with roommates, or in a sorority or fraternity house.

This period of time in an individual's life may lead to adverse health behaviors such as low physical activity, frequent intake of fast food, binge drinking, cigarette smoking, driving drunk, poor stress management, and inadequate sleep (Laska, Pasch, 
Lust, Story, \& Ehlinger, 2009). Poor stress management and credit card death were both associated with increased health risk behaviors (Nelson, Lust, Story, \& Ehlinger, 2008). Laska, Pasch, Lust, Story \& Ehlinger (2009) grouped students into four different classes based upon their risk behaviors. They found that $40 \%$ of their female sample were grouped into class one and were considered to have poor health based upon lifestyle and wellness factors. This group was more likely to have poor dietary, exercise, and sleeping habits. $24.3 \%$ of their female population was grouped in class two and considered "high risk." This group had the highest probability of smoking, binge drinking, driving drunk, and engaging in intoxicated sexual behaviors. This group also reported poor fruit and vegetable consumption. Majority of the men were grouped into class three indicating that they were less likely to have frequent fast food and poor fruit/vegetable intake (Laska, Pasch, Lust, Story, \& Ehlinger, 2009).

\section{Dietary Trends in College Students}

The 'typical college diet' has been described by Harris (2017) as consuming ramen noodles, pizza, and beer. This allowed students to normalize four years of unhealthy eating as a regular part of the collegiate experience. When asked to reflect upon their diet, students defined 'junk food' as highly processed, fast food, and sweets while 'healthy foods' were defined as fruits and vegetables (Harris, 2017). The Dietary Guidelines for Americans 2015-2020 define healthy eating as a consumption of fruits, vegetables, whole grains, low fat milk products, along with lean meats, fish, poultry, beans, eggs, and nuts. According to the American College Health Association (ACHA) National College Health Assessment (NCHA) in 2017, 83.9\% of students rated their 
health as "good, very good, or excellent," yet, only $62.3 \%$ reported having one to two servings of vegetables per day. Similarly, in a study by (Davy, Benes, \& Driskell, 2006) women and men (59.7\% versus $41.9 \%)$ agreed/strongly agreed that they ate too much sugar, $57.4 \%$ of women and $28.6 \%$ of men believed they needed to lose weight, yet $66.4 \%$ of respondents agreed/strongly agreed that they consumed a healthful diet. Although some students may understand what a healthy diet is, some use college as an explanation as to why they eat the way they do. One student from (Harris, 2017) stated "Overall, my diet is what a college student's should be. It is fast, cheap, practical." Similar opinions were found by Deliens, Clarys, Bourdeaudhuij, \& Deforche (2014) in that students reported easiness and convenience as being one of the biggest factors influencing food choices. Other factors that seem to influence eating behaviors in college students include pleasure and taste, social influence, university characteristics, access to food, cost of food, socio-cultural normal and values, home education, and media (Sogari, Velez-Argumedo, Gomez, \& Mora, 2018; Deliens, Clarys, Bourdeaudhuji, \& Deforche, 2014) . One participant indicated that seeing other people eat healthy may make them feel more inclined to eat healthy (Sogari, Velez-Argumedo, Gomez, \& Mora, 2018). This social influence may also result in someone purchasing food on campus as opposed to packing food from home depending on what the rest of the group is doing (Deliens, Clarys, Bourdeaudhuij, \& Deforche, 2014). Food choices will also rely heavily on what foods are available. A 2013 study found that approximately $45 \%$ of students made three or more purchases from a campus area source per week. Frequently purchasing food or beverage from the campus area was associated with a higher consumption of fat and 
added sugars. Students who frequently brought food from home had a higher intake of dairy, fruits, vegetables, calcium, and fiber (Pelletier \& Laska, 2013). On top of the various social and environmental factors that affect dietary intake, nutrition knowledge has also been a noteworthy influence.

\section{College Students' Food Knowledge}

Food Knowledge has shown to play an important role in food choices. In a study by Yahia, Brown, Rapley, \& Chung (2016), fat intake differed based upon knowledge, college major, and gender. Females students scored higher on a nutrition knowledge survey than males and consumed significantly less saturated fat, and cholesterol. Science majors and students who were on a diet also consumed less total fat, saturated fat, and cholesterol. In a 2009 study, Ha \& Caine-Bish found that a class-based nutrition intervention resulted in an increased intake of fruits and vegetables among students of both genders (Ha \& Caine-Bish, 2009). This suggests that having interventions in place to improve students' dietary intake may be a beneficial way to counteract the impact of an unhealthy collegiate diet.

According to Deliens et al. (2014), students believed that in order for one to make changes to eating patterns, dietary knowledge is required and that a lack of information may be the cause of low nutritional awareness (Barzegari, Ebrahimi, Azizi, \& Ranjbar, 2011). Multiple studies have shown that college students generally rate their diet as 'healthy' (American College Health Association, 2017; Poobalan, Aucott, Clarke, \& Smith, 2014; Schroeter \& House, 2015). Students under the age of 21 were less likely to consider their diets as healthy and were more likely to report a lower consumption of 
vegetables, and a higher consumption of snacks and "fizzy drinks" (Poobalan, Aucott, Clarke, \& Smith, 2014; Schroeter \& House, 2015). In the American College Health Association National College Health Assessment in 2017, 62.3\% of college students reported having one to two servings of vegetables per day while $8.3 \%$ reported having no servings of vegetables per day. In a previous study, students seemed to understand that eating fruits and vegetables is beneficial to their health, but indicated that some of the barriers to eating enough fruits and vegetables include an inability to cook, lack of money, and not "enjoying" healthy food (Poobalan, Aucott, Clarke, \& Smith, 2014). 


\section{CHAPTER 3}

\section{METHODOLOGY}

\section{Overview}

The purpose of this study was to analyze the perception and knowledge of MyPlate as well as dietary intake among college undergraduate students at a Midwestern University. Data collection was executed with two electronic questionnaires sent via email (Appendix) that contained questions related to the knowledge and perception of MyPlate. The independent variable for the initial survey was knowledge. The dependent variable was perception. This research was approved by the Institutional Review Board (IRB) at Kent State University.

\section{Participants}

Study participants were recruited from currently enrolled college students at a large Northeast Ohio state university during the spring semester. A total of 24,997 individuals were contacted and invited to participate. A total of 1,539 students volunteered to complete the questionnaire. Students who participated were first asked to report their age and student status. Students who reported to be younger than $18(n=8)$, older than $24(n=227)$, or graduate students $(n=78)$ were excluded from participating farther. Students who were not able to identify an image of MyPlate were also excluded 
$(n=53)$. Students who completed the initial questionnaire were invited to volunteer for a second, longer survey. A convenience sample of the first 30 students to volunteer to participate further were selected to complete the ASA24 (National Cancer Institute \& National Institute of Health, 2019). Participants for the initial survey $(n=1,539)$ were not compensated for their time. Participants who completed the ASA24 $(n=30)$ were compensated with a $\$ 10$ gift card and entered into a drawing for a $\$ 50$ gift card with a one out of 30 chance of winning.

\section{Instrumentation}

Data was collected with the use of two surveys. The first survey consisted of general demographic questions, as well as questions regarding knowledge and perception of MyPlate (Appendix A). The second survey consisted of the automated selfadministered 24-hour recall system from the National Institute of Health (NIH) and National Cancer Institute (Appendix B). These two surveys were the only instruments used for this study. This form of data collection was approved by the University Institutional Review Board.

\section{Survey Development}

This survey used two different surveys; one developed through Qualtrics, and one used from the National Institute of Health and National Cancer Institute. There were various components to these surveys and specific information was gathered from each.

\section{Survey Components}

The first survey had three main components; a demographic section, a knowledge section, and a perception section. The demographic section asked about age, marital 
status, gender, ethnicity, living status, class standing, major, and enrollment status in a basic nutrition course, and dieting history. The next section, part II of the survey asked about knowledge of MyPlate. The exclusion question consisted of an unlabeled graphic of the MyPlate image and asked participants to identify the image with six multiple choice answers to choose form. Students who answered that question correctly moved on to answer more knowledge questions regarding the sections of MyPlate and recommendations from the choosemyplate.gov website. The third section, part III of the survey, asked for information regarding people's perception of MyPlate.

Part I: demographics. Part I of the survey included a total of 12 questions regarding the demographics of the responding individual. The first questions asked for the participant's age. If an individual answered that they were $<18$ or $>24$ the survey terminated, and students were not asked any further questions. The next questions asked about gender and class standing, whether they are on a Kent State Dining Services meal plan, marital status, whether they have children, class standing in NUTR23511, and race/ethnicity. The last few questions in part I asked participants to rate the healthfulness of their diet, asked if they considered themselves to be on a special diet in the past 6 months, and asked them to identify a picture of MyPyramid.

Part II: exclusion question and knowledge questions. The exclusion question included an unlabeled picture of MyPlate and students were asked to correctly identify the image. They had the option to choose between six multiple choice answers (1) “MyPyramid,” (2) “Dietary Guidelines for Americans," (3) "MyPlate," (4) "Recommended Dietary Allowance (RDA)," (5) "Food Guide Pyramid," (6) "Unsure." 
Students who did not correctly choose MyPlate were asked if they would like to participate in a second survey and were asked to exit the survey. Individuals who answered the question correctly were asked where they had seen the image and if they had ever visited www.choosemyplate.gov. Following those questions students were tested on their knowledge of MyPlate. There was a total of 13 knowledge questions.

Part III: perception questions. Part III of the survey included 7 perception questions. This section presented with statements about the helpfulness of MyPlate when making food decisions and students were asked to choose from (1) "Strongly agree," (2) “Agree," (3) "Neither agree nor disagree," (4) “Disagree," (5) "Strongly disagree.”

\section{Data Collection Procedures}

An e-mail batch was generated based upon enrollment at Kent State University. Emails were obtained through Kent State University's Registrar Office. The survey was emailed to a total of 24,997 students using the Qualtrics emailing system. Students under the age of 18 or older than 24 were excluded. Graduate students were excluded as well as those who were unable to identify a picture of MyPlate were asked to exit the survey. At the conclusion of the online survey, students were invited to participate in another survey regarding dietary intake. They provided their e-mail and were sent a link and login information to ASA24. All students who participated received a \$10 gift card compensation and were entered into a drawing for a $\$ 50$ gift card compensation. ASA24 generated data included how much of each food group students consumed versus what the recommendations are. This data compared dietary intake between students who perceived MyPlate as being easy to understand and useful, versus students who perceive 
MyPlate as difficult to understand and not useful. Responses were collected through Qualtrics. The survey could have been started at any time and on any device with internet access.

\section{Data Analysis Procedures}

Statistical analysis will be using SPSS software version 21 (IBM, New York). Descriptive statistics that were analyzed include means, frequencies, and standard deviations. The survey and diet analysis included quantitative data. The perception questions were scored by coding a five-point Likert-style scale. Strongly disagree was coded for as " 1 " and strongly agree was coded for as " 5 ." A score of " 1 " indicated a negative perception and " 5 " indicated a positive perception. A Pearson's Correlation was run to look at the relationship between MyPlate knowledge and the perception of MyPlate utility. A p-value of $<0.05$ was used to indicate significance in the data. Descriptive statistics were gathered from ASA24 to look at adherence to MyPlate recommendations based upon 24-hour recalls. 


\section{CHAPTER IV \\ JOURNAL ARTICLE}

\section{Introduction}

The United States has had some sort of food guidance symbol in place since 1916 (ChooseMyPlate, 2018). Most Americans remember the Food Guide Pyramid, developed in 1992, and the MyPyramid, developed in 2005. The United States Department of Agriculture along with Health and Human Services developed the Dietary Guidelines for Americans (DGA) every five years since 1980. These guidelines reflect the advancements in scientific knowledge and translate it into nutrition guidelines in order to promote health in the United States (United States Department of Agriculture \& U.S. Department of Agriculture, 2015). Food guides are now meant to reflect recommendations from the DGA in a simplified and consumer-friendly manner. USDA officials believed the pyramid was overly complex which resulted in its replacement in 2011 with the MyPlate (Washington Post, 2011).

The MyPlate promotes a healthy eating style with an emphasis on variety, amount, and nutrition; choosing foods and beverages low in saturated fat, sodium, and added sugar; starting with small changes; and supporting healthy eating for everyone. The MyPlate is divided into four compartments which include fruits, vegetables, whole grains, and protein foods. These recommendations are based on an eating pattern that promotes a healthy body weight, supports nutrient adequacy, and reduces risk of chronic disease (United States Department of Agriculture \& U.S. Department of Agriculture, 
2015). According to NHANES data eighty percent of the population consumed too few vegetables and seventy percent consumed too few fruits. Over half of consumed too much fat, sodium, and added sugars which have all been linked to multiple chronic disease when consumed in excess (McCullough, et al., 2002; Cordain, et al., 2005). The percent of obese individuals in the United States has been on the rise since 2007-2008. Six in ten adults have at least one chronic disease, while four in ten have two or more chronic diseases (CDC, 2018). Overweight and obesity has been associated with an increased risk of heart attack, stroke, heart failure, type 2 diabetes, and some cancers (World Cancer Research Fund \& American Institute for Cancer Research, 2007; Mahan, Escott-Stump, \& Raymond, 2012; World Health Organization, 2017). In 2017, heart disease is one of the leading causes of death in the United States (Center of Disease Control and Prevention, 2017).

Despite initial enthusiasm about MyPlate, it does not appear that people with access to these guidelines are benefiting from them. Additionally, little research has been done to look at whether the MyPlate guidelines are being used and whether they are effective. According to National Health and Nutrition Survey (NHANES) data from 2017 , about $25 \%$ of adolescents age and less than $20 \%$ of adults $20-29$ were familiar with MyPlate. Although the MyPlate website offers resources for all age groups, there is no data to suggest how often those resources are being used (ChooseMyPlate, 2018). The 2018 Food and Health Survey conducted by the International Food Information Council Foundation asked 1,009 individuals how familiar they were with MyPlate and just over ten percent indicated that they had seen the image and knew a lot about it. 
College students are a particular population that could benefit from basic nutrition knowledge. Their diets are typically low in fruits, vegetables, and fiber (Huang, et al., 2003)Food choices in college appear to be influenced by taste, convenience, price, social influence, socio-cultural norms and values, home education, and media (Harris, 2017; Sogari, Velez-Argumedo, Gomez, \& Mora, 2018). Students who live on or near campus and frequently purchase food from the campus area may consume more fat and added sugars than students who bring food from home (Pelletier \& Laska, 2013). Nutrition education may be a positive influence on student's eating behavior. A Ha \& Caine-Bish (2009) found that a class-based nutrition intervention resulted in an increased intake of fruits and vegetables. Students have reported that in order to make changes to one's eating pattern, knowledge is required (Deliens, Clarys, Bourdeaudhuji, \& Deforche, 2014). The MyPlate could be a useful tool in promoting healthy eating behaviors amongst college students. The ChooseMyPlate website has resources available specifically for college students which include tips for the dining hall, staying fit on campus, using a mini fridge, eating on a budget, and more. The purpose of this study was to determine whether increased knowledge of MyPlate would improve perception of MyPlate. It was hypothesized that knowledge of MyPlate would affect perception. This study also looked at dietary patterns among college undergraduate students and how closely their 24-hour recalls matched MyPlate recommendations. 


\section{Methodology}

\section{Overview}

The purpose of this study was to look at the relationship between MyPlate knowledge and the perception of its utility amongst undergraduate students at a Midwestern University. Data collection was executed with two separate electronic questionnaires (Appendix A). Survey I was post-test only and contained questions relating to demographics, knowledge of MyPlate, and perception of MyPlate utility. Quantitative data and descriptive statistics including mean, standard deviations, and frequencies, were collected. A Pearson's Correlation was run on this data to look at the relationship between knowledge and perception. Survey II was also post-test only. Quantitative data and descriptive statistics were collected.

\section{Participants}

Participants were a convenience sample of undergraduate students at a large Midwestern university enrolled in the 2019 spring semester. The sample included both females and males between the ages of 18-24 as to analyze students who fall into the category of a typical undergraduate student. Exclusion criteria included age, graduate students, and the ability to identify MyPlate. In survey I, participants were presented a blank image of MyPlate and asked to identify it. Those who were unable to identify the image were terminated from the survey.

\section{Instrumentation}

Two surveys were used in this study. The first survey was created on Qualtrics and had three main components; a demographic section, a knowledge section, and a 
perception section (Appendix A). This survey contained a total of 44 questions. The second survey used was the Automated Self-Administered 24-Hour Dietary Assessment Tool (ASA24) taken from the National Cancer Institute. This survey was only distributed via email link to 30 students who volunteered to participate by providing their email following the first survey.

Qualtrics survey. The first section of this survey was comprised of 11 demographic questions. This section probed participants on age, gender, ethnicity, class standing, marital status, living arrangements, major, and enrollment in an entry level nutrition course. Additionally, students were asked to rate the healthfulness of their diet and if they had considered themselves to be on some sort of restricted diet in the past 6 months. The next section of this survey asked questions regarding knowledge of MyPlate. Participants were first asked to identify a blank image of MyPlate. If the participant was unable to identify the image, they were asked to exit the survey. This was the exclusion question. Students who successfully identified MyPlate moved onto additional knowledge questions. This section was comprised of 13 questions (not including the exclusion question). The final section of this survey analyzed participant's perception of the usefulness and effectiveness of MyPlate. Participants were asked to choose their level of agreement or disagreement with the following statements based upon a five-point Likert scale. Seven statements were provided, and students could choose from five answers: "strongly agree," "agree," "neither agree nor disagree," "disagree," and "strongly disagree." At the end of the survey, students were asked if they 
would like to participate in a second survey where a $\$ 10$ gift card compensation would be provided along with the chance to win a $\$ 50$ gift card compensation.

ASA24 survey. A total of 30 students were recruited for this survey. This was a convenience sample taken from the Qualtrics survey. The ASA24-2018 is a selfadministered automated dietary analysis tool that collects data on 24-hour food recalls. Participants were asked to provide a list of the foods and drinks consumed over the past 24 hours. Food intake is categorized based upon eating occasion (breakfast, lunch, dinner, snacks). Participants are also asked about details of the foods and beverages consumed. For example, how the food was prepared (roasted, grilled, etc.), whether there were any additions such as salad dressing, coffee creamer, etc., and where the source of the food and beverages. Participants were then promoted to review their recall and were again asked about any possible forgotten foods. After participants finalized their 24-hour recall they were then asked questions regarding usual intake. Finally, they were asked about supplements consumed.

\section{Data Collection Procedures}

Following Institutional Review Board (IRB) approval, an email list was generated from the University's Registrar Office based upon spring 2019 enrollment at Kent State University. The first survey was created on Qualtrics and a link was sent via e-mail to 24,997 students. No compensation was provided for their participation. The survey remained active for nine days. Responses were collected using the 2018 version of Qualtrics. The survey could have been started at any time and completed on any device with internet access. Responses were completely anonymous aside from students who 
volunteered to participate in the second survey by providing their email upon completion of the first survey.

The first 30 undergraduate students to complete the first survey and provide their email were contacted and provided with a username and password along with the link to ASA24. Students were informed they had four days to complete this part of the survey. Participants who did not complete the survey were contacted again on March $9^{\text {th }}$ and the deadline was extended to the following day. The results from the surveys were stored in the ASA24 researcher website. An Excel spreadsheet was generated and downloaded which contained information for each participant as well as combined results from all participants. The only data used for this study was combined totals of fruit, vegetable, grains, protein, and dairy consumption. No data regarding micronutrients was used.

\section{Data Analysis Procedures}

Data was collected, organized, and ran through the Statistical Package for Social Sciences (SPSS) Version 25. Descriptive statistics were used to analyze mean, standard deviations, and frequencies across the data set. A Pearson's Correlation was used to measure the correlation between knowledge of MyPlate and perception of the usefulness and effectiveness of MyPlate. Knowledge questions were scored for each participant using an answer key. Each knowledge question answered correctly resulted in " 1 " point. Zero points were given for incorrect responses. Question 13 was the exclusion question and was not scored. This question asked participants to correctly identify a blank MyPlate graphic. Questions 14-16 were general questions that asked participants to indicate where they have seen MyPlate, rate their level of agreeance to whether they use 
the image to guide food decisions, and to indicate whether they had ever visited www.choosemyplate.gov. These questions were not scored and were not counted toward perception or knowledge questions.

Questions 17-29 tested and scored participants on their knowledge of MyPlate. Participants had a total of 13 points they could have received. Perception questions 3036 were scored by coding the five-point Likert scale, where "strongly disagree" was coded for as " 1 " and "strongly agree" was coded for as " 5 ." The average perception score was 3.04 .

\section{Results}

This next section will discuss results from both the Qualtrics Survey as well as the ASA24 survey. The Qualtrics Survey was available to all male and female undergraduate students enrolled in the spring semester. Participants for the ASA24 survey were recruited from those who participated in the Qualtrics survey.

\section{Qualtrics Survey}

Of the 24,997 surveys that were sent, 1,557 responses were recorded, resulting in a $6.62 \%$ response rate. Students were eliminated from the study if they were under the age of 18 , or over the age of $24(n=241)$, or if they were graduate students $(n=91)$. Additionally, students were also excluded if they were unable to identify the MyPlate graphic $(n=126)$, or if they did not complete $80 \%$ or more of the knowledge and/or perception questions $(n=84)$. Based on those criteria, 542 students were excluded from this study and data was taken from a total of 1,018 .

\section{ASA24 Survey}


A total of 22 ASA24 surveys were collected. The survey could be started at any time; however, participants were unable to exit out of the survey and come back. Responses had to be collected at once. The purpose of this survey was to collect 24-hour recalls from participants and compare actual intake to MyPlate recommendations. Data for intake of fruits, vegetables, proteins, grains, and dairy was collected through ASA24.

\section{Demographics}

The demographics data pertaining to the participants of this study are shown in Table 3. The survey participants' age ranged from 18 to 24 with a mean age of 20 for both males and females. Participants had the opportunity to select more than one ethnicity and majority of participants identified as strictly white/Caucasian (83.4\%). The population included a variety of majors such as nutrition, nursing, business, biology, public health, etc. A majority of the participants were female $(80.3 \%)$. Our population was similar to that of the University in that a majority of participants were Caucasian females. At the University, $74 \%$ of students are Caucasian and $63 \%$ are female.

Participants were asked about their enrollment status in a basic college-level nutrition course. About $66 \%$ of students had never taken the class before, and roughly one in four students had taken the class in the past $(26.5 \%)$. Seventy-six students were currently enrolled (7.4\%). Participants were almost completely evenly spread amongst the four class levels.

\section{Knowledge of MyPlate}

The results from the knowledge assessment of MyPlate are displayed in Table 4. Correct answers are indicated in bold. Question 21 had the highest number of correct 
answers $(82.9 \%)$. This question stated, “The current dietary guidelines recommend limiting saturated fat, added sugar, and sodium." Question 23 was missed the most frequently with only $10.8 \%$ of participants answering correctly. This question stated, "The currently dietary guidelines recommend making one third of grain consumption come from whole grains."

Another question that stood out was \#23 which stated, "vegetarians and vegans are able to utilize this graphic when making food choices." Just about half of participants chose "true" which was the correct answer. This indicates that half of the population did not know whether vegetarians and vegans could utilize the MyPlate. We did not ask if participants were vegetarian or vegan, however, if anyone in the group who answered "no" were vegetarian or vegan, they already would not be using MyPlate as they would not believe it applied to them.

\section{Perception of MyPlate Utility}

The results from the assessment on perception of MyPlate utility are presented in Table 5. Using a five-point Likert Scale ranging from strongly agree (1) to strongly disagree (5), participants were able to indicate how they perceived certain statements about MyPlate. There were only two statements in which majority of the participants indicated a positive perception by choosing to agree or strongly agree. Question 30 had $67.3 \%$ of participants agree or strongly agree that the MyPlate graphic was easy to understand, and question 33 had $61.5 \%$ of participants agree or strongly agree that the MyPlate graphic can be used by anyone in making healthy food decisions. There were also only two statements in which majority of the participants indicated a negative 
perception by choosing to disagree or strongly disagree with the statement. Question 32 had $71 \%$ of participants indicate that they disagreed or strongly disagreed with the statement "I often use this graphic to help guide me in making food choices." Question 34 had $55.7 \%$ of respondents indicate that they disagreed or strongly disagreed with the statement, "I believe many people currently use this graphic to help them make healthy food choices."

Table 3

Demographics of Undergraduate College Students Surveyed at a Midwestern University on MyPlate Knowledge and Perceived Utility $(N=1,018)$

\begin{tabular}{|c|c|c|}
\hline Demographics & $\mathrm{n}$ & $\%$ \\
\hline \multicolumn{3}{|l|}{ Q2 Gender } \\
\hline Female & 817 & 80.3 \\
\hline Male & 178 & 17.5 \\
\hline Non-binary & 19 & 1.9 \\
\hline Prefer not to say & 3 & 0.3 \\
\hline Prefer to self-describe & 1 & 0.1 \\
\hline \multicolumn{3}{|l|}{ Q3 Class level } \\
\hline Freshman & 252 & 24.8 \\
\hline Sophomore & 261 & 25.6 \\
\hline Junior & 232 & 22.8 \\
\hline Senior & 273 & 26.8 \\
\hline \multicolumn{3}{|l|}{ Q8 College nutrition course (NUTR23511) } \\
\hline Currently Enrolled & 76 & 7.5 \\
\hline Taken the class in the past & 270 & 26.5 \\
\hline Never taken the class & 671 & 65.9 \\
\hline
\end{tabular}


Table 4

Answers to Knowledge Questions Regarding MyPlate from College Students at a Midwestern State University $(N=1,018)$.

\begin{tabular}{l} 
Item \\
\hline Q17 What is represented by the blue circle in the upper \\
right-hand corner?
\end{tabular}
right-hand corner?

Water

Oils

Dessert

Dairy

Unsure n

Vegetables, grains, fats, fruit

Grains, fats, fruits, proteins

Unsure

Protein, vegetables, grains, fats

Fruits, proteins, vegetables, grains

Fats, fruits, proteins, vegetables

n

Q18 What food groups are represented by the four triangles?

Q19 Which of the following is NOT represented in the graphic above?

$$
\text { Dairy }
$$

Fruit

Grains

Protein

Water

Q20 The current dietary guidelines recommend filling half your plate with fruits and vegetables

True

False 
Table 4 continued

Answers to Knowledge Questions Regarding MyPlate from College Students at a Midwestern State University $(N=1,018)$.

\begin{tabular}{lll}
\hline Item & $\mathrm{n}$ & $\%$
\end{tabular}

Q21 The current dietary guidelines recommend limiting saturated fat, added sugar, and sodium.

\section{True}

False

\section{Unsure}

844

47

124

616

110

290

Unsure

True

False

Q23 Vegetarians and vegans are able to utilize this graphic when making food choices

True

False

Unsure
4.6

12.2

Q24 This graphic was created to serve as a weight loss

plan

True

60

5.9

False

76.7

Unsure

170

Q25 Which of these foods CANNOT be considered a protein?

Nuts

Seeds

Beans

15

1.5

Peas

All of these foods can be considered a protein

489

48.0

None of these foods can be considered a protein
32

3.1 
Table 4 continued

Answers to Knowledge Questions Regarding MyPlate from College Students at a Midwestern State University $(N=1,018)$.

\begin{tabular}{|c|c|c|}
\hline Item & $\mathrm{n}$ & $\%$ \\
\hline \multicolumn{3}{|c|}{ Q26 1 cup of $100 \%$ fruit juice can count as a serving of } \\
\hline \multicolumn{3}{|l|}{ fruit } \\
\hline True & 387 & 38.0 \\
\hline False & 372 & 36.5 \\
\hline Unsure & 258 & 25.3 \\
\hline \multicolumn{3}{|c|}{ Q27 Eating one serving of vegetables once per day is } \\
\hline \multicolumn{3}{|c|}{ enough to meet dietary guideline recommendations (one } \\
\hline \multicolumn{3}{|c|}{ serving $=1$ cup of raw or cooked vegetables } \\
\hline True & 223 & 21.9 \\
\hline False & 570 & 56.0 \\
\hline Unsure & 224 & 22.0 \\
\hline \multirow{2}{*}{\multicolumn{3}{|c|}{$\begin{array}{l}\text { Q28 Fruit must be fresh and not canned, frozen, or dried in } \\
\text { order to count as fruit intake }\end{array}$}} \\
\hline & & \\
\hline True & 199 & 19.5 \\
\hline False & 596 & 58.5 \\
\hline Unsure & 222 & 21.8 \\
\hline \multicolumn{3}{|c|}{ Q29 The current dietary guidelines recommend consuming } \\
\hline \multicolumn{3}{|c|}{ fat-free or low-fat dairy products } \\
\hline True & 580 & 57.0 \\
\hline False & 157 & 15.4 \\
\hline Unsure & 279 & 27.4 \\
\hline
\end{tabular}


Table 5

Perception of MyPlate Utility amongst Undergraduate College Students at a Midwestern University $(N=1018)$.

Item

$\%(\mathrm{n})$

\begin{tabular}{|c|c|c|c|c|c|}
\hline & $\begin{array}{l}\text { Strongly } \\
\text { Agree (1) }\end{array}$ & Agree (2) & $\begin{array}{c}\text { Neither Agree } \\
\text { nor Disagree } \\
\text { (3) }\end{array}$ & Disagree (4) & $\begin{array}{c}\text { Strongly } \\
\text { Disagree (5) }\end{array}$ \\
\hline $\begin{array}{l}\text { Q30 This graphic is easy to } \\
\text { understand. }\end{array}$ & $18.8(191)$ & $48.5(494)$ & $19.8(202)$ & $11.3(11)$ & $1.6(16)$ \\
\hline $\begin{array}{l}\text { Q31 I believe this graphic is a } \\
\text { useful tool in helping me make } \\
\text { food decisions daily. }\end{array}$ & $7.9(80)$ & $32.7(333)$ & $31.1(317)$ & $20.2(206)$ & $7.9(80)$ \\
\hline $\begin{array}{l}\text { Q32 I often use this graphic to help } \\
\text { guide me in making food choices. }\end{array}$ & $1.9(19)$ & $8.9(91)$ & $18.2(185)$ & $37.8(385)$ & $33.2(338)$ \\
\hline $\begin{array}{l}\text { Q33 I believe this graphic can be } \\
\text { used by anyone to help them make } \\
\text { healthy food choices. }\end{array}$ & $11.9(121)$ & $49.6(505)$ & $21.7(221)$ & $13.5(137)$ & $3.2(33)$ \\
\hline $\begin{array}{l}\text { Q34 I believe many people } \\
\text { currently use this graphic to help } \\
\text { them make healthy food choices. }\end{array}$ & $3.8(39)$ & $15.8(161)$ & $24.6(250)$ & $40.0(407)$ & $15.7(160$ \\
\hline $\begin{array}{l}\text { Q35 This graphic is a more } \\
\text { practical tool than other } \\
\text { recommendation tools such as the } \\
\text { Food Guide Pyramid or RDAs. }\end{array}$ & $10.4(106)$ & $37.2(379)$ & $37.2(379)$ & $12.6(128)$ & $2.5(25)$ \\
\hline $\begin{array}{l}\text { Q36 I would rather follow a diet } \\
\text { from an online source than use this } \\
\text { guideline to make food choices. }\end{array}$ & $7.9(80)$ & $26.3(268)$ & $38.1(388)$ & $22.1(225)$ & $5.3(54)$ \\
\hline
\end{tabular}

Table 6

Knowledge and Perception Scores of Male and Female Undergraduate College Students at a Midwestern University $(N=993)$

\begin{tabular}{llccc}
\hline Gender & & $\mathrm{N}$ & $\begin{array}{c}\text { Knowledge } \\
\text { Score (\% correct) }\end{array}$ & Perception Score \\
\hline Male & 178 & 46.7 & 2.9 \\
& Female & 815 & 51.4 & 3.1 \\
\hline
\end{tabular}

When looking at gender, both males and females only answered about $50 \%$ of the knowledge scores correctly on average. Females scored slightly higher on knowledge questions then did males (51.4\% versus $46.7 \%$ respectively). This is consistent with 
results from Yahia, Brown, Rapley, \& Chung (2016) who found females had a significantly higher nutrition knowledge score than males in their survey. This particular study also found a negative correlation between nutrition knowledge and intake of saturated fat and cholesterol.

Table 7 displays the difference in knowledge scores between males and females who were currently or previously enrolled in a college-level nutrition course versus males and females who were never enrolled in a nutrition course. Table 8 shows the difference in perception scores for these groups. Previous research has shown that specifically females may be more receptive to nutrition information than males (Tagtow \& Raghavan, 2017).

Table 7

Percent of Knowledge Questions Answered Correctly Between Males and Females either Previously/Currently Enrolled in a Nutrition Class Versus Males and Females Never Enrolled in a Nutrition Class

\begin{tabular}{lcc}
\hline Item & $\begin{array}{c}\text { Percent of Knowledge Questions } \\
\text { Answered Correctly }\end{array}$ & $\mathrm{N}$ \\
\hline $\begin{array}{l}\text { Females currently or previously enrolled in } \\
\text { NUTR23511 }\end{array}$ & $56 \pm 16$ & 303 \\
Females never enrolled in NUTR23511 & $48 \pm 18$ & 514 \\
$\begin{array}{l}\text { Males currently or previously enrolled in } \\
\text { NUTR23511 }\end{array}$ & $51 \pm 14$ & 41 \\
Males never enrolled in NUTR23511 & $45 \pm 17$ & 137 \\
\hline
\end{tabular}

**Knowledge scores presented as percentages out of 100 
Table 8

Difference in Perception Scores Between Males and Females Previously/Currently Enrolled in a Nutrition Class Versus Males and Females Never Enrolled in a Nutrition Class

\begin{tabular}{lcc}
\hline \multicolumn{1}{c}{ Item } & Average Perception Score & $\mathrm{N}$ \\
\hline $\begin{array}{l}\text { Females currently or previously enrolled } \\
\text { in NUTR23511 }\end{array}$ & $3.11 \pm .66$ & 303 \\
Females never enrolled in NUTR23511 & $3.04 \pm .58$ & 514 \\
Males currently or previously enrolled in & $2.93 \pm .73$ & 41 \\
NUTR23511 & & 137 \\
Males never enrolled in NUTR23511 & $2.91 \pm .63$ & \\
\hline
\end{tabular}

**Perception scores reported out of 5

\section{Correlation Between Knowledge and Perception of MyPlate}

Table 6 presents the correlation between knowledge and perception of MyPlate. A Pearson Correlation showed a 2-tailed significance of $\mathrm{p}<0.05$ with a weak correlation of .111. This indicated that there was a significant trend as knowledge increased, perception of the utility of MyPlate increased as well. However, this correlation was weak indicating that knowledge does not necessarily largely impact perception.

Table 9

Correlation Between Knowledge and Perception of MyPlate amongst Undergraduate College Students at a Midwestern State University $(N=1,018)$

\begin{tabular}{llcc}
\hline & & Average Perception & Knowledge Score \\
\hline Average Perception & Pearson Correlation & 1 & .111 \\
& Sig. (2-tailed) & & .000 \\
Knowledge Score & $\mathrm{N}$ & 1018 & 1018 \\
& Pearson Correlation & .111 & 1 \\
& Sig. (2-tailed) & .000 & 1018 \\
\hline
\end{tabular}

**. Correlation is significant at the 0.01 level (2-tailed) 


\section{Adherence to MyPlate from Sample Population}

The second survey was completed by 22 participants who were recruited at the end of part I. The purpose of this survey was to look at adherence to MyPlate recommendations. Dietary Intake was broken down into each food group. Results of that are shown in Table 10 . There was only a $26.6 \%$ conformity to MyPlate recommendations. Recommendations for adults 19-30 years old is to consume, on average, 2 cups of fruits, 2.5 cups of vegetables, 6.3 ounces of grains, 5.6 ounces of protein, and 3 cups of dairy. The average consumption of each food group is presented in table 10.

Table 10 Average Recommended Intake of Each Food Group Compared to Actual Average Intake From 24-hour Dietary Recalls

\begin{tabular}{llcc}
\hline Food Group & & Average Recommended Intake & Actual intake (Average) \\
\hline & Fruits & 2.0 cups & 0.75 cups \\
& Vegetables & 2.5 cups & 1.6 cups \\
& Grains & 6.3 ounces & 5.8 ounces \\
& Proteins & 5.6 ounces & 6.1 ounces \\
& Dairy & 3.0 cups & 1.5 cups \\
\hline
\end{tabular}

\section{Discussion}

Overall this study showed that knowledge of MyPlate can influence the perceived utility. As knowledge of MyPlate increased, perceived utility of MyPlate increased as well. When looking at dietary intake, we found that although students were able to identify a blank MyPlate graphic, dietary intake did not necessarily reflect the MyPlate recommendations. There was no correlation between increasing MyPlate knowledge and adherence to recommendations. 
Our hypothesis was that as knowledge of MyPlate increased, perceived utility of MyPlate would decrease. Meaning, as students became more knowledgeable about MyPlate, they would be more likely to view it as a useful and effective tool and use it to guide their food decisions. Our study found that as knowledge increased, perception actually increased as well. Although the correlation was weak, these results indicate that understanding MyPlate may negatively impact the perception of its utility. The more knowledgeable students were on the MyPlate, the less likely they were to believe it to be useful.

Conformity to MyPlate was heavily driven by protein. We found that protein was the only food group in which a majority of the participants met or exceeded recommendations. The other four food groups were frequently not met. These results indicate that being able to recognize MyPlate is not enough for college students to actually implement the recommendations into their dietary intake.

\section{Characteristics of Study Population}

Data collected from this study indicated that majority of the participants were female $(80.3 \%)$. Majority of participants were 19 years old $(26.3 \%)$, with an average age of 20.0 for females 20.3 for males. Participants ranged relatively consistently across class levels with $24.8 \%$ freshman, $26.8 \%$ sophomores, $22.8 \%$ juniors, and $26.8 \%$ seniors. Majority of participants identified themselves as strictly white/Caucasian (83.4\%). Twenty-five students indicated their major was nutrition or nutrition/dietetics $(2.1 \%)$, $7.5 \%$ participants were currently enrolled in a college-level nutrition course (NUTR23511), 26.5\% of students had taken that class in the past and $65.9 \%$ of students 
had never taken the class. The current study showed that $21 \%$ of students classified their diet as very healthy or healthy and $46.4 \%$ of students classified their diet as somewhat healthy. This is similar to results from previous surveys. The ACHA (2017) found that $83.9 \%$ of college students described their health as good, very good, or excellent; and in 2018, nearly $90 \%$ of participants in the 2018 Food and Health Survey described their health status as good, very good, or excellent (International Food Information Council Foundation, 2018). Poobalan, Aucott, Clarke, \& Smith (2014) found that adults 20 years and older were confident that their diet was healthy while adults 18-19 reported more irregular diet patterns.

In the present study, after participants were excluded based on age and graduate level, 126 were excluded for not being able to identify MyPlate. This was $11.0 \%$ of the population. This left 1,018 participants who were able to identify MyPlate (89\%). This number was unexpectedly high based upon previous research. NHANES data found that only $25 \%$ of adolescents age $16-19$, and less than $20 \%$ of adults $20-29$ were familiar with MyPlate (Tagtow \& Raghavan, 2017). The 2018 Food and Health Survey conducted by the International Food Information Council Foundation asked 1,009 individuals how familiar they were with MyPlate and just over ten percent indicated they had seen it and know a lot about it; and 30\% indicated they had never seen it before (International Food Information Council Foundation, 2018). This may be due to the fact that the International Food Information Council Foundation surveyed individuals between the ages of 18-80. MyPlate was released in 2011 and is typically taught in schools. Anyone over the age of 32 in that survey would have most likely been out of college and not been 
exposed to MyPlate. Majority of those participants were likely more familiar with the Food Guide Pyramid, as it was released in 1992, updated in 2005, and not replaced until 2011 (ChooseMyPlate, 2011). In the case of the present study, participants would have been between the ages of 10 and 16 when MyPlate was released and may have been exposed to it in the classroom. Therefore, it makes sense that majority of this population could at least identify MyPlate compared to the population from the 2018 Food and Health Survey. These studies did not only look at college students like ours did which may also be a reason for such large differences in people who were familiar versus people who were not. A 2013 study of students at a health fair found that $45.1 \%$ had seen the MyPlate icon previously, and only $11.8 \%$ had visited the www.choosemyplate.gov website. However, the sample of this study was small $(n=51)$.

\section{MyPlate Knowledge}

The present study also found that although majority of students could identify MyPlate, the average knowledge score was only 50.5\%. Almost all participants $(82.9 \%)$ knew that the current dietary guidelines recommend limiting saturated fat, added sugar, and sodium. Interesting to note that although those three nutrients should be limited, over $60 \%$ of Americans either meet or exceed the recommendations (United States Department of Agriculture \& U.S. Department of Agriculture, 2015). The question that was most often missed stated "the currently dietary guidelines recommend making one third of grain consumption come from whole grains" and participants were to choose an answer from true, false, and unsure. The DGA recommends getting half of grains from whole grains, but only $10.8 \%$ of participants chose the correct answer indicating that 
students may not understand exact portion sizes. This may indicate that simply providing a graphic showing the proper foods to eat, does not necessarily translate the recommended portion sizes.

Question 23 stated "vegetarians and vegans are able to utilize this graphic when making food choices. While $49.3 \%$ of participants chose the correct answer, "true," the rest of the participants either chose "false" or unsure." This is interesting because this could potentially leave out an entire population of people who could be benefitting from MyPlate recommendations but are not because they do not understand that it applies to them as well. On top of this, $41.1 \%$ of participants thought that peas could not be considered a protein. Again, this would be important to understand especially for anyone who is vegetarian or vegan.

There does not appear to be a lack of knowledge about fruit and vegetable recommendations. Majority of participants (73.2\%) knew that MyPlate recommends filling half of one's plate with fruits and vegetables. When asked, students defined healthy foods as consisting of fruits and vegetables, or vice versa (Davy, Benes, \& Driskell, 2006; Harris, 2017). People are aware that fruits and vegetables are beneficial to their health, and that in order to live a long, happy life it is important to have healthy eating habits (Funk \& Kennedy, 2016). However, future health did not seem to be a main concern for students (Poobalan, Aucott, Clarke, \& Smith, 2014). Students do not only choose their foods based upon healthfulness; their food choices are influenced by taste, social influence, previous eating habits, physical environment, university characteristics, and individual factors (Deliens, Clarys, Bourdeaudhuij, \& Deforche, 2014; Poobalan, 
Aucott, Clarke, \& Smith, 2014). More information regarding adherence to MyPlate recommendations will be discussed further on.

\section{Perception of MyPlate Utility}

The present study revealed that majority of participants $(67.3 \%)$ agreed or strongly agreed that the MyPlate graphic is easy to understand. Also, $61.5 \%$ of participants agreed or strongly agreed that the MyPlate graphic can be used by anyone in making healthy food decisions, however, only $10.8 \%$ of participants indicated that they deliberately use the MyPlate graphic to help them make food choices on a daily basis. A majority of participants (55.7\%) also do not believe other people currently use this graphic to help them make healthy food choices. Males were slightly more likely to have a more positive perception of MyPlate (2.0) versus females (3.1). There appears to be a disconnect between perceived utility and actual use of the MyPlate guidelines. This is important because although the graphic created to promote dietary changes is easy to understand, does not mean that anyone is benefitting from it or that it is being executed properly.

There was a significant correlation between knowledge and perception of MyPlate in this study. As knowledge of MyPlate increased, perception of the utility of MyPlate increased as well. A Pearson's Correlation value of .111 was found. Although significant, this correlation was weak, indicating that knowledge of MyPlate only has a small impact on how students perceive the utility of MyPlate. In previous studies, students indicated that lack of information is the main cause for low nutrition awareness (Barzegari, Ebrahimi, Azizi, \& Ranjbar, 2011), however, our study showed that 
knowledge does not necessarily translate into practice. Although this was the case, some studies showed that intervention, specifically designed for college students, may have an impact on dietary intake. Ha \& Caine-Bish (2009) found that a class-based nutrition intervention significantly increased intake of fruits and vegetables in college students. This suggests that targeted intervention may be more beneficial in promoting proper nutrition.

\section{Dietary Patterns and Adherence to MyPlate}

The current study found that although students were able to identify MyPlate, their dietary intake did not greatly reflect the MyPlate recommendations. Of the 22 people who provided 24-hour recalls through ASA24, only one consumed enough fruit, and three consumed enough vegetables. The average amount of fruit consumed was 0.9 cups while MyPlate recommends 2 cups for males and females between ages of 19-30. The average amount of vegetables consumed was 1.8 cups while MyPlate recommends 2.5 cups for males and females age 19-30. It was expected that both fruit and vegetable intake was low no recent research articles were reviewed that reported Americans consuming sufficient quantities of either food group. NHANES data showed that over $60 \%$ of the population one year and older was below the recommended amount for both fruits and vegetables (United States Department of Agriculture \& U.S. Department of Agriculture, 2015). The American College Health Association found that $62.3 \%$ of students reported having 1-2 servings of vegetables per day, while $8.3 \%$ reported have none. According to Poobalan, Aucott, Clarke, \& Smith (2014) barriers to fruit and vegetable consumption included inability to cook, not "enjoying" healthy food, and lack 
of money. Therefore, although students know the importance of fruit and vegetable consumption and know that MyPlate recommends filling half of one's plate with fruits and vegetables, students are still not consuming enough.

Grain consumption was also low by an average 0.8 one-ounce equivalents. A typical Western diet is associated with high intake of refined grains, sugar, saturated fat and sodium (United States Department of Agriculture \& U.S. Department of Agriculture, 2015). According to NHANES data, over $50 \%$ of the population was at or above the recommended intake of grains. College students who eat on campus have higher intake of added sugars compared to students who pack food from home (Pelletier \& Laska, 2013). In our study, almost half of the population (46.9\%) indicated that they were on a campus dining plan, indicating much of student food choices are coming from campus options.

Protein was a driving factor for what little MyPlate adherence was showcased in this study. It was the only food group that at least $50 \%$ of queried participants were at or above recommendations in. The average intake of protein consumed was 6.4 ounces, and the average recommendation was 5.6 ounces. This is similar to NHANES data which found over $50 \%$ of the population met or exceeded recommended protein foods (United States Department of Agriculture \& U.S. Department of Agriculture, 2015). It was not surprising to report that protein adherence was fairly good. As (Layman, 2014) pointed out that there has been a culture shift toward protein. Fitness magazines have made protein the focal point of nutrition; and food companies have delivered products high in protein while also focusing on consumer demand for convenience, taste, and cost. This 
focus on and adherence to protein consumption showcases the idea that social and traditional media has a measurable impact on American dietary trends. Protein adherence to conform to a fad diet, such as the ketogenic diet, is different from meeting MyPlate standards. With a focus on very low carbohydrate, high fat, and moderate protein, ketogenic dieters would deliberately be under-consuming the other food groups. While MyPlate does highlight the importance of adequate protein for muscle health and healthy aging, just as much if not more emphasis needs to be put on fruits, vegetables, and whole grains for their ability to help in the obesity and chronic disease epidemic. This emphasis may need to come from sources, such as media, in order to make a population-based impact on dietary trends.

\section{Limitations}

As with any research design, there were some limitations that existed within this study. The first limitation was the validity and reliability of the questionnaire. The first questionnaire used was created by the researcher and not taken from a previously validated questionnaire. The second limitation was self-reported data. The survey respondents self-reported and therefore valid data cannot be guaranteed. Participants could have looked up answers to knowledge questions online or answered questions strictly to volunteer their participation in the second survey in which compensation was provided. The third limitation was that participation was voluntary in this study. Students who have a higher interest or are more knowledgeable in this topic may have been more likely to volunteer their participation. Additionally, the use of a convenience sample has an inherent bias by not necessarily being randomizable to a greater 
population. All students who participated were from the same Midwestern University, but the food choices and nutritional education available at that campus may not reflect those of all college aged individuals. Another limitation is that MyPlate is meant to serve as an average eating pattern over a week. Since we only completed a 24-hour recall, students technically could be meeting recommendations over the course of the week. Lastly, the majority of participants in this study were white/Caucasian females and care must be taken when considering populations that were not comprehensively sampled.

\section{Conclusion}

Overall, the current study pointed out the fact that knowledge of MyPlate does not necessarily influence adherence to MyPlate recommendations. Although a majority of students were able to identify MyPlate, very few actually consumed adequate fruits, vegetables, or grains, and most met or exceeded protein. This indicates that only $20 \%$ of the MyPlate recommendations are likely to be met by this this population over the course of a single day. Although there was a significant correlation between knowledge and perceived utility of MyPlate, a majority of participants indicated that they do not use the MyPlate on a daily basis to make food decisions. There is a gap between nutrition knowledge and nutrition adherence.

As stated earlier, food choices, specifically among college students, are not solely based on perceived healthfulness of food. Food choices are influenced by social environment, physical environment, macro environment, university characteristics and individual preference, state of mind, knowledge, body image, and values/norms/beliefs. To assume that publishing population-based guidelines is adequate in shifting dietary 
behaviors may be naïve. The Dietary Guidelines not only need to be emphasized throughout the individual's lifetime, but a focus needs to be put on "how" and not just "why." Students were able to identify what foods they need to eat, and studies have shown that individuals know what eating patterns promote overall health, however, adherence is low both nationally and at the college level. 
APPENDICES 
APPENDIX A

MYPLATE KNOWLEDGE AND PERCEPTION SURVEY 
Appendix A

MyPlate Knowledge and Perception Survey

Q1 How old are you?
$\bigcirc<18$
○ 19
○ 20
○ 21
○ 22
○ 23
○ 24
O $>24$

Q2 What gender do you identify as?
O Male
○ Female
Non-binary/ third gender
Prefer to self-describe
Prefer not to say 
Q3 What is your class standing?

Freshman

Sophomore

○ Junior

○ Senior

O Graduate Student

Q4 What is your major?

Fill-in answer here

Q5 Are you on a Kent State Dining Services meal plan?

○ Yes

○ No

Q6 What is your marital status?

O Married

$\bigcirc$ Widowed

O Divorced

○ Separated

Never married 
Q7 Do you have children?

○ Yes

O No

Q8 Please select your status regarding a college-level nutrition class, NUTR23511

I have taken the class in the past

I am currently enrolled in the class

I have never taken the class before

Q9 What is your race/ethnicity?
- African American
- American Indian/Native American
O Asian/Pacific Islander
Hispanic
O White/Caucasian
Other, please specify

Q10 How would you rate the healthfulness of your diet?

V Very Healthy 

$\bigcirc$ Healthy
O Somewhat Healthy
Neither healthy nor unhealthy
O Somewhat Unhealthy
O Unhealthy
○ Very Unhealthy

Q11 In the past 6 months, did you ever consider yourself to be on a specialized diet for any specific reason? For example, ketogenic, low calorie, low sodium, high protein, liquid, etc.
○ Yes
○ No
O Unsure

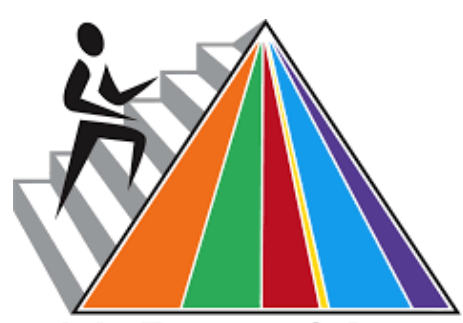

Q12 What is the name of this graphic?
O MyPyramid
○ Dietary Guidelines for Americans 
O MyPlate

Recommended Dietary Allowance (RDA)

Food Guide Pyramid

○ Unsure

Part II: Exclusion question and knowledge questions

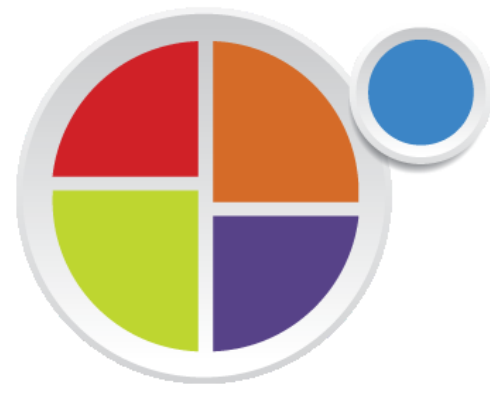

Q13 What is the name of this graphic?

O MyPyramid

○ Dietary Guidelines for Americans

MyPlate

O Recommended Dietary Allowance (RDA)

○ Food Guide Pyramid

O Unsure

Q14 Where have you seen or heard of this graphic?

○ Classroom

○ Cafeteria 
○ Doctor's office

O Online

○ym

O Magazine

○ Book

Other

Q15 I often use this graphic to help guide me in making food choices

Strongly agree

○ Agree

Neither agree nor disagree

Disagree

Strongly disagree

Q16 Have you ever visited www.choosemyplate.gov?

○ Yes

○ No

Unsure

Use the below image to answer the following questions. If you are unsure of the answer please do not guess, click "Unsure." 


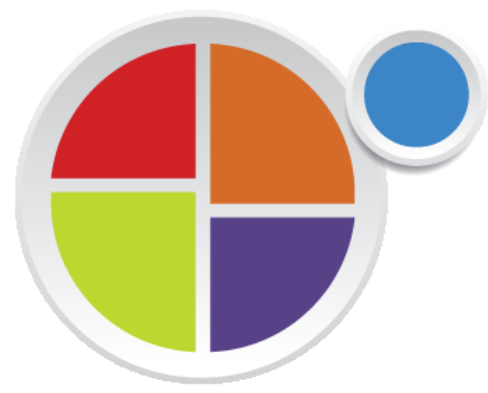

Q17 What is represented by the blue circle in the upper right-hand corner?

Dairy

$\bigcirc$ Desserts

○ Oils

O Water

Q18 What food groups are represented by the four triangles?

Proteins, vegetables, grains, fats

Fruit, proteins, vegetables, grains

Fats, fruits, proteins, vegetables

O Grains, fats, fruits, proteins

Vegetables, grains, fats, fruit

Q19 Which of the following is NOT represented on the graphic above?

○ Water

O Protein 

○ Dairy
O Vegetables
○ Grains
$\bigcirc$ Fruit

Q20 The current dietary guidelines recommend filling half of your plate with fruits and vegetables
$\bigcirc$ True
False
O Unsure

Q21 The current dietary guidelines recommend limiting saturated fat, added sugar, and sodium
○ True
False
Unsure

Q22 The current dietary guidelines recommend making one third of your total grain consumption come from whole grains
○ True
False 
○ Unsure

Q23 Vegetarians and vegans are able to utilize this graphic when making food choices

○ True

- False

○ Unsure

Q24 This graphic was created to serve as a weight loss plan
○ True
O False
○ Unsure

Q25 Which of these foods CANNOT be considered a protein?
○ Nuts
Seeds
O Beans
○ Peas
All of these foods can be considered a protein
None of these foods can be considered a protein

Q26 1 cup of $100 \%$ fruit juice can count as a serving of fruit 
○ True

O False

○ Unsure

Q27 Eating one serving of vegetables once a day is enough to meet dietary guideline recommendations. (One serving $=1$ cup of raw or cooked vegetables, or 2 cups of dark leafy greens)

○ True

False

○ Unsure

Q28 Fruit must be fresh and not canned, frozen, or dried in order to count as fruit intake

○ True

False

○ Unsure

Q29 The current dietary guidelines recommend consuming fat free or low-fat dairy products

○ True

False 
○ Unsure

\section{Part III Perception Questions}

Use the graphic below to answer the following questions.

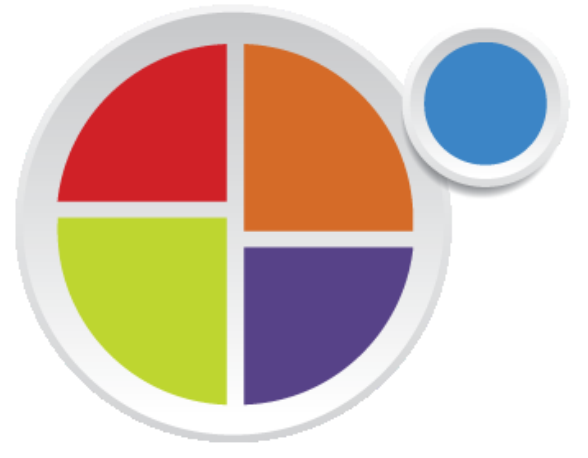

Q30 This graphic is easy to understand.

Strongly agree

O Agree

Neither agree nor disagree

○isagree

Strongly disagree

Q31 I believe this graphic is a useful tool in helping me make food decisions daily.

Strongly agree

○ Agree

Neither agree nor disagree

○ Disagree 
Strongly disagree

Q32 I often use this graphic to help guide me in making food choices.

Strongly agree

○ Agree

$\bigcirc$ Neither agree nor disagree

Disagree

O Strongly disagree

Q33 I believe this graphic can be used by anyone to help them make healthy food choices.

Strongly agree

○ Agree

Neither agree nor disagree

○isagree

Strongly disagree

Q34 I believe many people currently use this graphic to help them make healthy food choices.

Strongly agree

○ Agree 
Neither agree nor disagree

Disagree

Strongly disagree

Q35 This graphic is a more practical tool than other recommendation tools such as the Food Guide Pyramid or RDA's.

Strongly agree

○ Agree

Neither agree nor disagree

Disagree

○ Strongly disagree

Q36 I would rather follow a diet from an online source (internet/social media) than use this guideline to make food choices.

Strongly agree

○ Agree

Neither agree nor disagree

○ Disagree

O Strongly disagree 
APPENDIX B

RECRUITMENT EMAIL 


\section{Appendix B}

\section{Recruitment Email}

\section{Dear Prospective Survey Participant,}

My name is Sarah Radcliff and I am a graduate student in nutrition/dietetics. I am writing to let you know about an opportunity to participate in a voluntary research study about the current dietary guidelines. This study is being conducted by Dr. David Sharp and myself at Kent State University.

Participation includes answering an online survey. This survey will take less than 10 minutes. Following the survey, you will be asked if you would like to participate in an additional online dietary recall survey. The first 30 students who provide their email will be emailed the ASA24 dietary recall survey. All 30 students who participate will receive a \$10 gift card as compensation for their time. All 30 students will also be entered into a drawing to win a $\$ 50$ gift card. The odds of winning the $\$ 50$ gift card are 1 in 30 . Students who only answer the first online survey portion and do not complete a dietary recall will not receive compensation.

All undergraduate students between the ages of 18-24 have the opportunity to participate in this study.

If you would like additional information about this study, please contact us at dsharp7@kent.eduor sradclif@,kent.edu.

Thank you for your consideration, and once again, please do not hesitate to contact us if you are interested in learning more about our project.

\section{Follow this link to the Survey:}

Take the Survey

Or copy and paste the URL below into your internet browser:

https://kent.qualtrics.com/jfe/form/SV 2iv2FwQCLRAvuol?Q DL=enBjhD0Lw5QA0w 5_2iv2FwQCLRAvuol_MLRP_bygI6XSp76LDaXr\&Q_CHL=email

Follow the link to opt out of future emails:

Click here to unsubscribe

Sincerely,

Sarah Radcliff 
APPENDIX C

MYPLATE GRAPHIC 


\section{Appendix C}

\section{MyPlate Graphic}

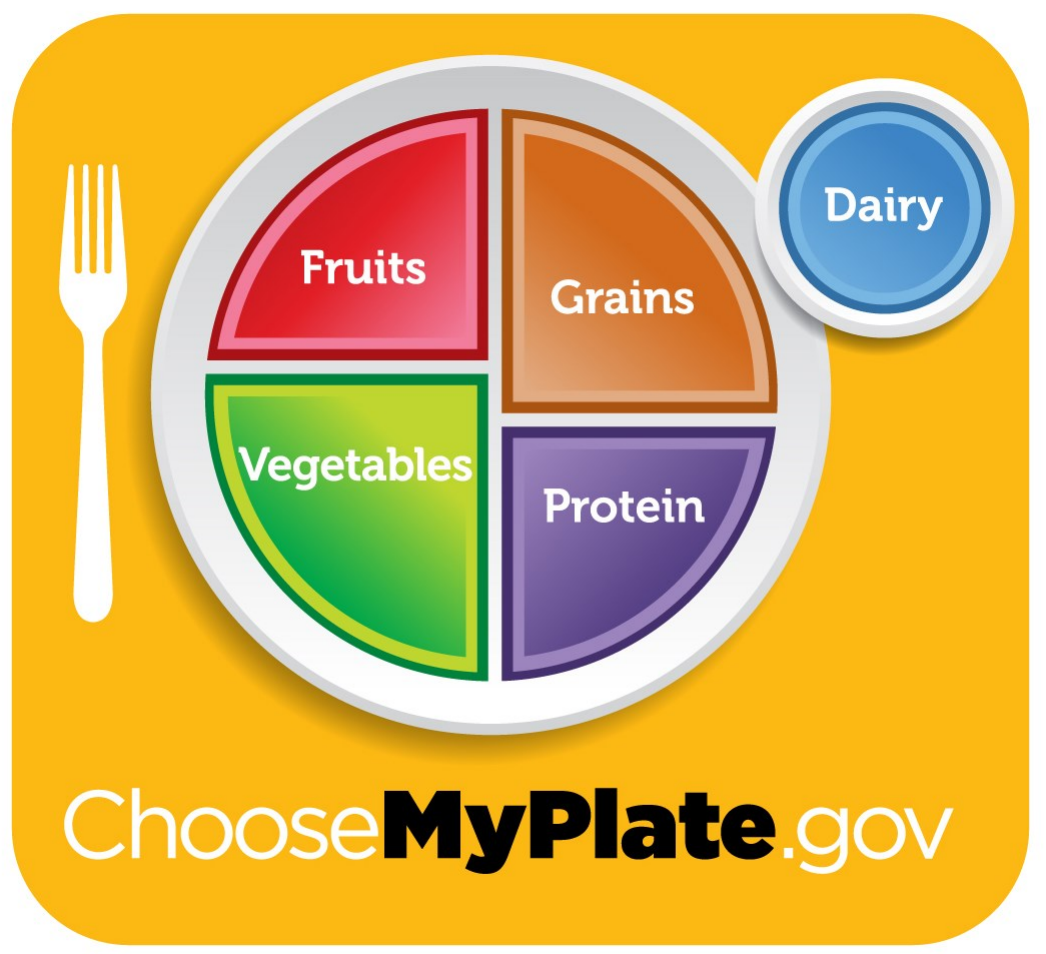

Figure 1. MyPlate: Current food guide graphic released in 2011 
APPENDIX D

FOOD GUIDE PYRAMID GRAPHIC 


\section{Appendix D}

\section{Food Guide Pyramid Graphic}

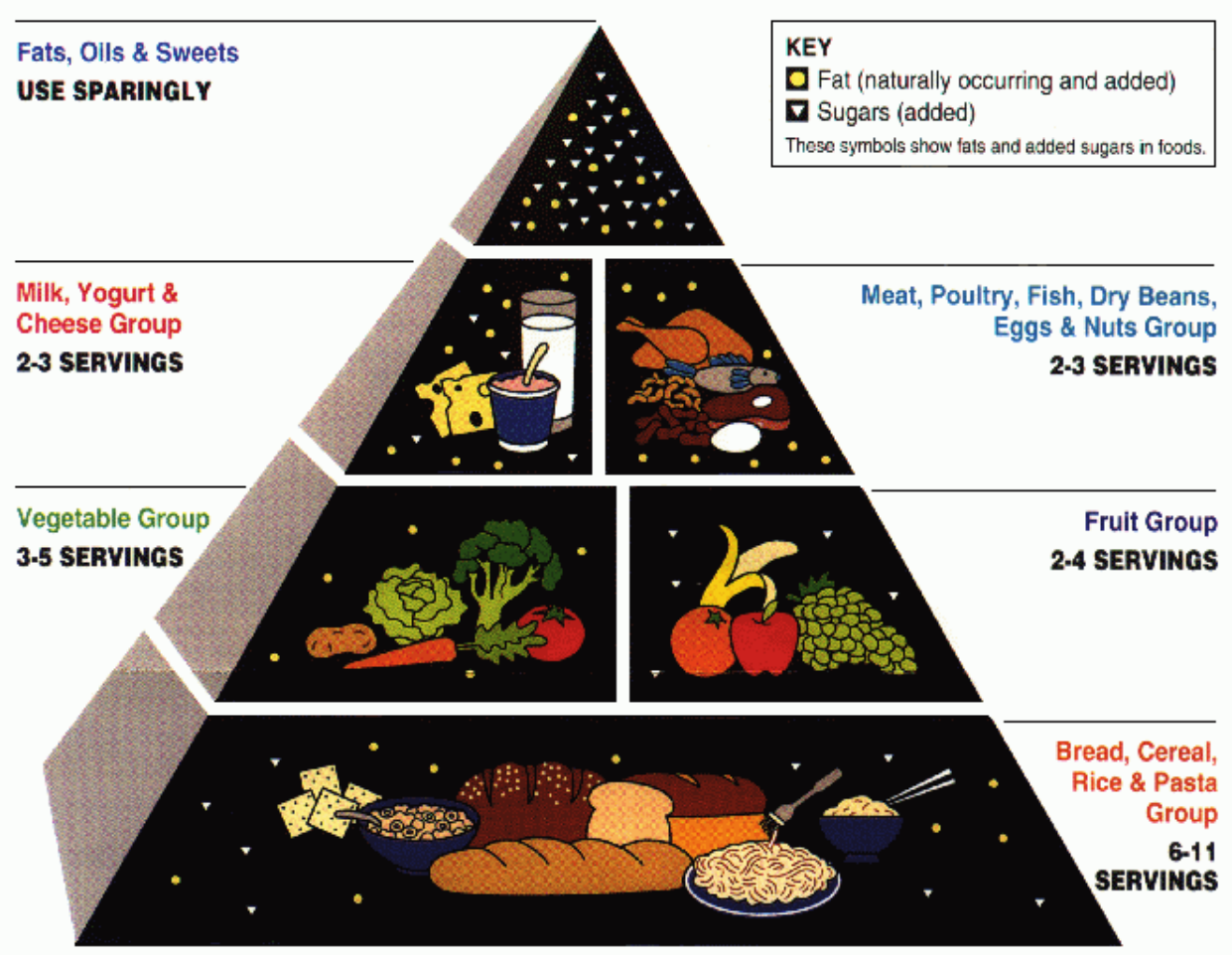

Figure 2. USDA's Food Guide Pyramid released in 1992 
REFERENCES 


\section{REFERENCES}

(n.d.).

(2015, February 9). Retrieved from National Cancer Institute:

https://www.cancer.gov/about-cancer/understanding/what-is-cancer

(2016, November 29). Retrieved from Centers for Disease Control and Prevention:

https://www.cdc.gov/cancer/dcpc/prevention/policies_practices/physical_activity/ guidelines.htm

(2017, November 28). Retrieved 11 11, 2018, from CDC.gov:

https://www.cdc.gov/heartdisease/facts.htm

(2017, May 17). Retrieved from World Health Organization: http://www.who.int/newsroom/fact-sheets/detail/cardiovascular-diseases-(cvds)

(2017, May 11). Retrieved from ChooseMyPlate.gov: https://choosemyplateprod.azureedge.net/sites/default/files/printablematerials/ABriefHistoryOfUSDAF oodGuides.pdf

(2017, May). Retrieved from National Institute of Diabetes and Digestive and Kidney Diseases: https:/www.niddk.nih.gov/health-information/diabetes/overview/whatis-diabetes/type-2-diabetes

(2018, March 22). Retrieved from American Diabetes Association: http://www.diabetes.org/diabetes-basics/statistics/ 
(2018, April 27). Retrieved from National Cancer Institute: https://www.cancer.gov/about-cancer/understanding/statistics

(2018, October 25). Retrieved from CDC: https://www.cdc.gov/chronicdisease/resources/infographic/chronic-diseases.htm (2018, April 17). Retrieved from American Heart Association: https://www.heart.org/en/healthy-living/healthy-eating/eat-smart/sugar/addedsugars

Alberts, B., Johnson, A., Lewis, J., Raff, M., Roberts, K., \& Walter, P. (2002). Molecular Biology of the Cell. 4th edition. New York: Garland Science.

Alves, A., Viana, J., Cavalcante, S., Oliveira, N., Duarte, J., Mota, J., . . . Ribeiro, F. (2016, October 26). Physical activity in primary and secondary prevention of cardiovascular disease: overview updated. World Journla of Cardiology, 8(10), $575-583$.

American Cancer Society. (2019, January 8). Retrieved from https://www.cancer.org/latest-news/facts-and-figures-2019.html American College Health Association. (2017). ACHA. Retrieved February 2019, from American College Health Association National College Health Assessment II: Reference Group Executive Summary Fall 2017: https://www.acha.org/documents/ncha/NCHAII_FALL_2017_REFERENCE_GROUP_EXECUTIVE_SUMMARY.pdf 
American Diabetes Association. (2008, January). Nutrition recommendations and interventions for diabetes. Diabetes Care, 31(Supplement 1), S61-S78.

American Heart Association. (2017, May 31). Retrieved February 2018, from heart.org: https://www.heart.org/en/health-topics/consumer-healthcare/what-iscardiovascular-disease

American Heart Association. (2017, March 23). Retrieved from https://www.heart.org/en/healthy-living/healthy-eating/eat-smart/fats/trans-fat American Heart Association. (2019). Retrieved from https://professional.heart.org/idc/groups/ahamahpublic/@wcm/@sop/@smd/documents/downloadable/ucm_503396.pdf

American Institute for Cancer Research. (2019). Retrieved March 2019, from http://www.aicr.org/reduce-your-cancer-risk/recommendations-for-cancerprevention/

An, R. (2016). Fast-food and full-service restaurant consumption and daily energy and nutrient intakes in US adults. European Journal of Clinical Nutrition, 97-103.

Anderson, B., Rafferty, a., Lyon-Callo, S., Fussman, C., \& Imes, G. (2011). Fast-food consumption and obesity among michigan adults. American Journal of Public Health, 312-318.

Arnett, J. J. (2000, May). Emerging adulthood: a theory of development from the late teens through twenties. American psychologist, 55(5), 469-480.

Association, A. H. (2017, May 31). Retrieved from http://www.heart.org/en/healthtopics/consumer-healthcare/what-is-cardiovascular-disease 
Barzegari, A., Ebrahimi, M., Azizi, M., \& Ranjbar, K. (2011). A study of nutrition knowledge, attitudes and food habits of college students. World Applied Sciences Journal, 15(7), 1012-1017.

Bellisle, F. (2014). Meals and snacking, diet quality and energy balance. Physiology and Behavior, 38-43.

Benjamin, E., Virani, S., Callaway, C., Chamberlain, A., Chang, A., Cheng, S., \& Chiuve, S. (2018, March 20). Heart disease and stroke statistics-2018 update. Circulation, 137, e67-e492.

Benowitz, N., \& Burbank, A. (2016). Cardiovascular toxicity of nicotine: implications for electronic cigarette use. Trends in Cardiovascular Medicine, 26(6), 515-523.

Berge, A. (2008). How the ideology of low fat conquered America. Journal of the History of Medicine and Allied Sciences.

Betteridge, J. (2000, February). What is oxidative stress? Metabolism: Clinical and Experimental, 49(2), 3-8.

Bezerra, I., Curioni, C., \& Sichieri, R. (2012). Associations between eating out of home and body weight. Nutrition Reviews, 65-79.

Bhutani, S., Schoeller, D., Walsh, M., \& McWilliams, C. (2018). Frequency of eating out at both fast-food and sit-down restaurants was associated with high body mass index in non-large metropolitan communities in Midwest. American Journal of Health Promotion, 75-83.

Bombak, A. (2014). Obesity, health at every size, and public health police. American Journla of Public Health, e60-e67. 
Bray, G., Nielsen, S., \& Popkin, B. (2004, April 1). Consumption of high-fructose corn syrup in beverages may play a role in the epidemic of obesity. American Journal of Clinical Nutrition, 79(4), 537-543.

Cawley, J., \& Meyerhoefer, C. (2012). Medical care costs of obesity: an instrumental variables approach. Journal of Health Economics, 219-230.

Center of Disease Control and Prevention. (2017, November 28). CDC.gov. Retrieved February 2019, from https://www.cdc.gov/heartdisease/facts.htm

Center of Disease Control and Prevention. (2018, February 24). Retrieved from https://www.cdc.gov/diabetes/data/statistics/statistics-report.html

Centers for Disease Control and Prevention. (2017, August 29). Retrieved MARCH 2019, from https://www.cdc.gov/healthyweight/assessing/bmi/adult_bmi/index.html\#Why Centers for Disease Control and Prevention. (2019, February 4). Retrieved from https://www.cdc.gov/tobacco/data_statistics/fact_sheets/adult_data/cig_smoking/i ndex.htm

ChooseMyPlate. (2011, June). Retrieved from https://choosemyplateprod.azureedge.net/sites/default/files/relatedresources/ABriefHistoryOfUSDAFoo dGuides.pdf

ChooseMyPlate. (2018, July 19). Retrieved from https://www.choosemyplate.gov/MyPlate ChooseMyPlate. (2018, July 19). Retrieved from https://www.choosemyplate.gov/MyPlate 
Cordain, L., Eatin, S., Sebastian, A., Mann, N., Lindeberg, S., Watkins, B., . . . BrandMiller, J. (2005). Origins and evolution of the Western diet: health implications for the 21st century. American Journal of Clinical Nutrition, 341-354.

Dalen, J., Alpert, J., Goldberg, R., \& Weinstein, R. (2014, September ). The epidemic of the 20th century: coronary heart disease. The American Journal of Medicine, 127(9), 807-812.

Davy, S., Benes, B., \& Driskell, J. (2006, October). Sex differences in dieting trends, eating habits, and nutrition beliefs of a group of midwestern college students. Journal of the American Dietetic Association, 106(10), 1673-1677.

Davy, S., Benes, B., \& Driskell, J. (2006). Sex differences in dieting trends, eating habits, and nutrition beliefs of a group of midwestern college students. Journal of the American Dietetic Association, 106, 1673-1677.

Deliens, T., Clarys, P., Bourdeaudhuij, I. D., \& Deforche, B. (2014). Determinants of eating behaviour in university students: a qualitative study using focus group discussions. BMC Public Health, 14(53).

Deliens, T., Clarys, P., Bourdeaudhuji, I. D., \& Deforche, B. (2014). Determinants of eating behaviour in university students: a qualitative study using focus group discussions. BMC Public Health, 14(53).

DiSantis, K., Birch, L., Davey, A., Serrano, E., Zhang, J., Bruton, Y., \& Fisher, J. (2013). Plate size and children's appetite: effects of larger dishware on selfserved portions and intake. Pediatrics, e1451-e1458. 
Duffey, K., Pereira, r., \& Popkin, B. (2013). Prevalence and energy intake from snacking Brazil: analysis of the first nationwide individual survey. European Journal of Clinical Nutrition, 868-874.

Emken, E. A. (1984). Nutrition and biochemistry of trans and positional fatty acid isomers in hydrogenated oils. Ann. Rev. Nutr., 339-376.

Estruch, R., Ros, e., Salas-Salvado, J., Covas, M.-I., Corella, D., \& Aros, F. (2013, April 4). Primary prevention of cardiovascular disease with a Mediterranean diet. The New England Journal of Medicine, 368(14), 1279-1290.

Evert, A., Boucher, J., Cypress, M., Dunbar, S., Franz, M., Mayer-Davis, E., . . . Yancy, W. (2013, November). Nutrition therapy recommendations for the management of adults with diabetes. Diabetes Care, 36(11), 3821-3842.

Federal Occupational Health. (n.d.). PSC. Retrieved from https://foh.psc.gov/calendar/nutrition.html

Finkelstein, E., Trogdon, J., Cohen, J., \& Dietz, W. (2009, July 27). Annual medical spending attributable to obesity: prayer-and service-specific estimates. Retrieved from https://www.healthaffairs.org/doi/pdf/10.1377/hlthaff.28.5.w822 Food and Agriculture Organization of the United Nations. (2018). Retrieved from http://www.fao.org/nutrition/education/food-dietary-guidelines/regions/en/ Food and Drug Administration. (2018, June 12). Retrieved from https://www.fda.gov/food/resourcesforyou/consumers/ucm315393.htm 
(2007). Food, nutrition, physical activity, and the prevention of cancer: a global perspective. Washington DC: World Cancer Research Fund International; American Institute for Cancer Research.

Fryar, C., Highes, J., Herrick, K., \& Ahluwali, N. (2018). Fast food consumption among adults in the United States, 2013-2016. Hayattsville: Center of Disease Control and Prevention.

Funk, C., \& Kennedy, B. (2016, December 1). Pew Internet. Retrieved from Pew Research Center: http://www.pewinternet.org/2016/12/01/public-views-aboutamericans-eating-habits/

Gebel, E. (2012, November). Diabetes Forcast. Retrieved from http://www.diabetesforecast.org/2012/nov/more-kids-than-ever-have-type-2diabetes.html

Gropper, S., \& Smith, J. (2013). Advanced Nutrition and Human Metabolism (Vol. 6). Belmont, California: Cengage Learning.

Grosso, G., Bella, F., Godos, J., Sciacca, S., Rio, D. D., Ray, s., . . . Giovannucci, E. (2017). Possible role of diet in cancer: systematic review and multiple metaanalyses of dietary patterns, lifestyle factors and cancer risk. Nutrition Reviews, 405-419.

Ha, E.-J., \& Caine-Bish, N. (2009). Effect of nutrition intervention using a general nutrition course for promoting fruit and vegetable consumption among college students. Journal of Nutrition Education and Behavior, 41(2), 103-109. 
Hales, C., Carroll, M., Fryar, C., \& Ogden, C. (2017). Prevalence of obesity among adults and youth: United States, 2015-2016. Hyattsville: Centers for Disease Control and Prevention.

Harris, D. (2017, February 28). Just the "typical college diet": how college students use life stages to account for unhealthy eating. Symbolic Interaction, 40(4).

Hastert, T., \& White, E. (2016). Association between meeting the WCRF/AICR cancer prevention recommendations and colorectal cancer incidence: results from the VITAL cohort. Cancer Causes Control, 27(11), 1347-1359.

Haven, J., \& Maniscalco, S. (2014). MyPlate myths debunked. Journal of the Academy of Nutrition and Dietetics, 674-675.

Hess, J., Jonnalagadda, S., \& Slavin, J. (2016). What is a snack, why do we snack, and how can we choose better snacks? A review of the definitions of snacking, motivations to snack, contributions to dietary intake, and recommendations for improvement. American Society for Nutrition , 466-475.

Hruby, A., \& Hu, F. (2015). The epidemiology of obesity: a big picture. Pharmacoeconomics, 673-689.

Hruby, A., Manson, J., Qi, L., Malik, V., Rimm, E., Sun, Q., . . . Hu, F. (2016). Determinants and consequences of obesity. AJPH, 1656-1662.

Huang, T., Harris, K. J., Lee, R., Nazir, N., Born, W., \& Kaur, H. (2003). Assessing overweight, obesity, and physical activity in college students. Journal of American College Health, 52(2), 83-86. 
International Food Information Council Foundation. (2018). Foodinsight.org. Retrieved February 2019, from https://foodinsight.org/wp-content/uploads/2018/05/2018FHS-Report-FINAL.pdf

Johnson, G., \& Anderson, H. (2010). Snacking definitions: impact on interpretation of the literature and dietary recommendations. Critical Reviews in Food SCience and Nutrition, 848-871.

Kerver, J., Yang, E. J., Obayashi, S., Bianchi, L., \& Song, W. (2006). Meal and snack patterns are associated with dietary intake of energy and nutrients in US adults. Journal of the American Dietetic Association, 46-53.

Khan, N., Afaq, F., \& Mukhtar, H. (2010). Lifestyle as risk factor for cancer: evidence from human studies. Cancer Lett, 133-143.

Kit, B., Fakhouri, T., Park, S., Nielsen, S., \& Ogden, C. (2013, July 1). Trends in sugarsweetened beverage consumption among youth and adults in the United States: 1999-2010. The American Journal of Clinical Nutrition, 98(1), 180-188.

Know the Differences: Cardiovascular Disease, Heart Disease, Coronary Heart Disease. (n.d.). Retrieved from National Heart, Lung, and Blood Institute: https://www.nhlbi.nih.gov/sites/default/files/media/docs/Fact_Sheet_Know_Diff_ Design.508_pdf.pdf

Larson, N., Perry, C., Story, M., \& Neumark-Stzainer, D. (2006). Food preparation by young aduts is associated with better diet quality. Journal of the American Dietetic Association, 2001-2007. 
Laska, M. N., Pasch, K. E., Lust, K., Story, M., \& Ehlinger, E. (2009). Latent class analysis of lifestyle characteristics and health risk behaviors among college youth. The Journal of the Society for Prevention Research, 10(4), 376-386.

Layman, D. (2014). Eating patterns, diet quality and energy balance: a perspective about applications and future directions for the food industry. Physiology \& Behavior, 134, 126-130.

Lipoeto, N. I., Lin, K. G., \& Angeles-Agdeppa, I. (2012). Food consumption patterns and nutrition transition in South-East Asia. Public Health Nutrition, 1637-1643.

Loren Cordain, B. E.-M. (2005). Origins and evolution of the Western diet: health implications for the 21st century. American Journal of Clinical Nutrition, 341354.

Mahan, K., Escott-Stump, S., \& Raymond, J. (2012). Krause's Food and the Nutrition Care Process. St. Louis: Elsevier Saunders.

Maiorana, A., O'Driscoll, G., Goodman, C., Taylor, r., \& Green, D. (2002). Combined aerobic and resistance exercise improves glycemic control and fitness in type 2 diabetes. Diabetes Research and Clinical Practice, 56, 115-123.

Malik, V., Schulze, M., \& Hu, F. (2006, August). Intake of sugar-sweetened beverages and weight gain: a systematic review. American Journal of Clinical Nutrition, 84(2), 274-288.

Mattes, R. (2014). Energy intake and obesity: Ingestive frequency outweighs portion size. Physiology \& Behavior, 110-118. 
McCullough, M., Feskanich, D., Stampfer, M., Giovannucci, E., Rimm, E., Hu, F., . . . Willett, W. (2002). Diet quality and major chronic disease risk in men and women: moving toward improved dietary guidance. American Journal of Clinical Nutrition, 1261-1271.

Micha, R., Shulkin, M., Penalvo, J., Khatibzadeh, S., Singh, G., Rao, M., . . . Mozaffarian, D. (2017). Etiologic effects and optimal intakes of foods and nutrients for risk of cardiovascular diseases and diabetes: systematic reviews and meta-analyses from the Nutrition and Chronic diseases Expert Group (NutriCoDE). PLOS ONE, 1-25.

Mills, S., Brown, H., Wrieden, W., White, M., \& Adams, J. (2017). Frequency of eating home cooked meals and potential benefits for diet and health: cross-sectional analysis of a population-based cohort study. International Journal of Behavioral Nutrition and Physical Activity, 2-11.

Mitchell, N., Catenacci, V., Wyatt, H., \& Hill, J. (2011, December). Obesity: overview of an epidemic. The Psychiatric Clinics of North America, 34(4), 717-732.

Monsivais, P., Aggarwal, A., \& Drewnowski, A. (2014). Time spent on home food preparation and indicators of healthy eating. American Journal of Preventative Medicine, 796-802.

National Cancer Institute. (2018, April 27). cancer.gov. Retrieved February 2019, from https://www.cancer.gov/about-cancer/understanding/statistics

National Cancer Institute, \& National Institute of Health. (2019, February 1). Retrieved from ASA24: https://epi.grants.cancer.gov/asa24/ 
National Institute of Diabetes and Digestive and Kidney Diseases. (2016, November).

Retrieved from https://www.niddk.nih.gov/healthinformation/diabetes/overview/what-is-diabetes

Nelson, M., Lust, K., Story, M., \& Ehlinger, E. (2008, August). Credit card debt, stress and key health risk behaviors among college students. American Journal of Health Promotion, 22(6), 400-407.

Ogden, C., \& Carroll, M. (2010). Prevalence of overweight, obesity, and extreme obesity among adults: United States, trends 1960-1962 through 2007-2008. Center for Disease Control and Prevention.

Pantalone, K., Hobbs, T., Chagin, K., Kong, S., Wells, B., Kattan, M., . . . Burguera, B. (2017). Prevalence and recognition of obesity and its associated comorbidities: cross-sectional analysis of electronic health record data from a large US integrated health system. BMJ Open, 1-9.

Pelletier, J., \& Laska, M. (2013). Campus food and beverage purchases are associated with indicators of diet quality in college students. American Journal of Health Promotion, 28(2), 80-87.

Poobalan, A., Aucott, L., Clarke, a., \& Smith, W. (2014). Diet behaviour among young people in transition to adulthood (18-25 year olds): a mixed method study. Health Psychology and Behavioural Medicine, 2(1), 909-928.

Popkin, B., Armstrong, L., Bray, G., Caballero, B., Frei, B., \& Willett, W. (2006). A new proposed guidance system for beverage consumption in the United States. The American Journal of Clinical Nutrition, 83, 529-542. 
Ratner, R., \& Riis, J. (2014). Communicating science-based recommendations with memorable and actionable guidelines. PNAS, 13634-13641.

Ravera, A., Carubelli, V., Sciatti, E., Bonadei, I., Gorga, E., Cani, D., . . . Lombardi, C. (2016). Nutrition and cardiovascular disease: finding the perfect recipe for cardiovascular health. Nutrients, 1-27.

Raynor, H., Goff, M., Poole, S., \& Chen, G. (2015). Eating frequency, food intake, and weight: a systematic review of human and animal experimental studies. Frontiers in Nutrition.

Reedy, J., Krebs-Smith, S., Miller, P., Liese, A., Kahle, L., Park, Y., \& Subar, a. (2014). Higher diet quality is associated with decreased risk of all-cause cardiovascular disease, and cancer mortality among older adults. American Society for Nutrition, 881-889.

Roh, L., Braun, J., Chiolero, A., Bopp, M., Rohrmann, S., \& Faeh, D. (2014). Mortality risk associated with underweight: a census-linked cohort of 31,578 individuals with up to 32 years of follow-up. BMC Public Health, 1-9.

Romaguera, D., Vergnaud, A.-C., Peeters, P., Gils, C. H., Chan, D. S., Romieu, I., . . . Clavel-Chapelon, F. (2012, July 1). Is concordance with World Cancer Research Fund/American Institute for Cancer Research guidelines for cancer prevention related to subsequent risk of cancer? Results from the EPIC study. American Journal of Clinical Nutrition, 96(1), 150-163.

Roser, M., \& Ritchie, H. (2018, March). Our World Data. Retrieved from https://ourworldindata.org/cancer 
Schroeter, C., \& House, L. (2015). Fruit and vegetable consumption of college students: what is the role of food culture? Journal of Food Distribution Research, 46(3), $131-152$.

Schulze, M., Manson, J., \& Ludwig, D. (2004). Sugar-sweetened beverages, weight gain, and incidence of type 2 diabetes in young and middle-aged women. JAMA, 292(8), 927-934.

Schwedhelm, C., Boeing, H., Hoffmann, G., Aleksandrova, K., \& Schwingshackl, L. (2016). effect of diet on mortality and cancer recurrence among cancer survivors: a systematic review and meta-analysis of cohort studies. Nutrition Reviews, 737748.

Shanik, M., Xu, Y., Skrha, J., Dankner, R., Zick, Y., \& Roth, J. (2008, February). Insulin resistance and hyperinsulinemia; is hyperinsulinemia the cart or the horse? Diabetes Care, 31(2), S262-S268.

Sharp, D., \& Sobal, J. (2012). Using plate mapping to examine sensitivity to plate size in food portions and meal composition among college students. Appetite, 639645.

Sifferlin, A. (2016, January 7). TIME. Retrieved from http://time.com/4125642/dietaryguidelines-history/

Sigal, R., Kenny, G., Wasserman, D., Castaneda-Sceppa, C., \& White, R. (2006, June). Physical activity/exercise and type 2 diabetes. Diabetes Care, 29(6), 1433-1438. 
Smith, L., Ng, S., \& Popkin, B. (2013). Trends in US home food preparation and consumption: analysis of national nutrition surveys and time use studies from 1965-1966 to 2007-2008. Nutrition Journal, 2-10.

Sogari, G., Velez-Argumedo, C., Gomez, M., \& Mora, C. (2018). College students and eating habits: a study using an ecological model for healthy behavior. Nutrients, 10(12), 1823.

Tagtow, A., \& Raghavan, R. (2017). Assessing the reach of MyPlate using National Health and Nutrition Examination Survey data. Journal of the Academy of Nutrition and Dietetics, 181-183.

Taillie, L. S. (2018). Who's cooking? Trends in US home food preparation by gender, education, and race/ethnicity from 2003-2016. Nutrition Journal, 17(41).

Tordoff, M., \& Alleva, A. (1990). Effect of drinking soda sweetened with aspartame or high-fructose corn syrup on food intake and body weight. The American Journal of Clinical Nutrition, 51, 963-969.

U.S. Department of Health and Human Services, \& U.S. Department of Agriculture. (2015, December). Health.gov. Retrieved from https://health.gov/dietaryguidelines/2015/guidelines/

United States Department of Agriculture, \& U.S. Department of Agriculture. (2015). Dietary Guidelines for Americans 2015-2020. Retrieved March 2019, from health.gov: https:/health.gov/dietaryguidelines/2015/guidelines/ 
Vucenik, I., \& Stains, J. (2012, October 10). Obesity and cancer risk: evidence, mechanisms, and recommendations. ANNALS of the New York Academy of Sciences, 1271(1), 37-43.

Wadden, T., Webb, V., Moran, C., \& Bailer, B. (2012). Lifestyle modification for obesity: new developments in diet, physical activity, and behavior therapy. Circulation, 1157-1170.

Wardle, J., Haase, A., Steptoe, A., Nillapun, M., Jonwutiwes, K., \& Bellisle, F. (2004). Gender differences in food choice: the contribution of health beliefs and dieting. The Society of Behavioral Medicine, 27(2), 107-116.

Washington Post. (2011, June 2). Retrieved from https://www.washingtonpost.com/national/usda-replaces-food-pyramid-withmyplate-in-hopes-to-promote-healthiereating/2011/06/02/AGRE16HH_story.html?utm_term=.475d5839088a

Welsh, J., Lundeen, E., \& Stein, A. (2013, October). The sugar-sweetened beverage wars: public health and the role of the beverage industry. Current Opinion in Endocrinology \& Diabetes and Obesity, 20(5), 401-406.

What We Eat in America, NHANES 2013-2014. (2016). Retrieved from https://www.ars.usda.gov/ARSUserFiles/80400530/pdf/1314/Table_5_EIN_GEN - 13.pdf

White, J. (2008, December 1). Straight talk about high-fructose corn syrup: what it is and what it ain't. The American Journal of Clinical Nutrition, 88(6), 1716S$1721 \mathrm{~S}$. 
World Cancer Research Fund \& American Institute for Cancer Research. (2007).

Retrieved from Food, nutrition, physical activity, and the prevention of cancer: a global perspective:

http://www.aicr.org/assets/docs/pdf/reports/Second_Expert_Report.pdf

World Cancer Research Fund, \& American Institute for Cancer Research. (2007). Food, nutrition, physical activity, and the prevention of cancer: a global perspective. Washington DC.

World Health Organization. (2018, February 16). Retrieved March 2019, from https://www.who.int/topics/obesity/en/

Yahia, N., Brown, C., Rapley, M., \& Chung, M. (2016). Level of nutrition knowledge and its association with fat consumption among college students. BMC Public Health, 16(1047).

Yang, W., Kelly, t., \& He, J. (2008). Genetic epidemiology of obesity. Epidemiologic Reviews, 49-61.

Zelman, M., Tompary, E., Raymond, J., Holdaway, P., \& Mulvihill, M. L. (2010). Human Diseases: A Systematic Approach (Vol. 7). Upper Saddle River: Pearson.

Zong, G., Eisenberg, D., Hu, F., \& Sun, Q. (2016). Consumption of meals prepared at home and risk of type 2 diabetes: an analysis of two prospective cohort studies. PLOS Medicine, 1-18. 